\title{
Eight-component retrievals from ground-based MAX-DOAS observations
}

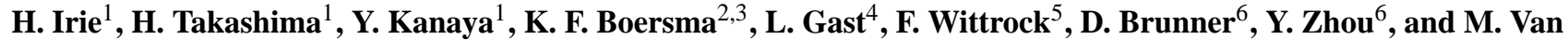 \\ Roozendael $^{7}$ \\ ${ }^{1}$ Research Institute for Global Change, Japan Agency for Marine-Earth Science and Technology, 3173-25 Showa-machi, \\ Kanazawa-ku, Yokohama, Kanagawa 236-0001, Japan \\ ${ }^{2}$ Climate Observations Department, Royal Netherlands Meteorological Institute, P.O. Box 201, \\ 3730 AE De Bilt, The Netherlands \\ ${ }^{3}$ Eindhoven University of Technology, Applied Physics, Eindhoven, The Netherlands \\ ${ }^{4}$ RIVM, P.O. Box 1, 3720 BA Bilthoven, The Netherlands \\ ${ }^{5}$ Institute of Environmental Physics, University of Bremen, Otto-Hahn-Allee 1, 28359 Bremen, Germany \\ ${ }^{6}$ Empa, Swiss Federal Laboratories for Materials Science and Technology, Ueberlandstrasse 129, \\ CH-8600 Dübendorf, Switzerland \\ ${ }^{7}$ Belgian Institute for Space Aeronomy, Ringlaan 3, 1180 Brussels, Belgium
}

Received: 30 December 2010 - Published in Atmos. Meas. Tech. Discuss.: 24 January 2011

Revised: 26 May 2011 - Accepted: 27 May 2011 - Published: 9 June 2011

\begin{abstract}
We attempt for the first time to retrieve lowertropospheric vertical profile information for 8 quantities from ground-based Multi-Axis Differential Optical Absorption Spectroscopy (MAX-DOAS) observations. The components retrieved are the aerosol extinction coefficients at two wavelengths, 357 and $476 \mathrm{~nm}$, and $\mathrm{NO}_{2}, \mathrm{HCHO}, \mathrm{CHOCHO}, \mathrm{H}_{2} \mathrm{O}$, $\mathrm{SO}_{2}$, and $\mathrm{O}_{3}$ volume mixing ratios. A Japanese MAX-DOAS profile retrieval algorithm, version 1 (JM1), is applied to observations performed at Cabauw, the Netherlands $\left(51.97^{\circ} \mathrm{N}\right.$, $4.93^{\circ} \mathrm{E}$ ), in June-July 2009 during the Cabauw Intercomparison campaign of Nitrogen Dioxide measuring Instruments (CINDI). Of the retrieved profiles, we focus here on the lowest-layer data (mean values at altitudes $0-1 \mathrm{~km}$ ), where the sensitivity is usually highest owing to the longest light path. In support of the capability of the multi-component retrievals, we find reasonable overall agreement with independent data sets, including a regional chemical transport model (CHIMERE) and in situ observations performed near the surface $(2-3 \mathrm{~m})$ and at the 200-m height level of the tall tower in Cabauw. Plumes of enhanced $\mathrm{HCHO}$ and $\mathrm{SO}_{2}$ were likely affected by biogenic and ship emissions, respectively, and an improvement in their emission strengths is suggested for better agreement between CHIMERE simulations and MAXDOAS observations. Analysis of air mass factors indicates
\end{abstract}

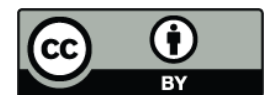

Correspondence to: $\mathrm{H}$. Irie (irie@jamstec.go.jp) that the horizontal spatial representativeness of MAX-DOAS observations is about $3-15 \mathrm{~km}$ (depending mainly on aerosol extinction), comparable to or better than the spatial resolution of current UV-visible satellite observations and model calculations. These demonstrate that MAX-DOAS provides multi-component data useful for the evaluation of satellite observations and model calculations and can play an important role in bridging different data sets having different spatial resolutions.

\section{Introduction}

Ground-based scattered sunlight observations in the UVvisible at several elevation angles (ELs) between the horizon and zenith, the so-called Multi-Axis Differential Optical Absorption Spectroscopy (MAX-DOAS) technique (e.g., Hönninger and Platt, 2002; Hönninger et al., 2004; Wittrock et al., 2004; Irie et al., 2008a), have come into wide use recently. Similar to well-established twilight zenith stratospheric observations, MAX-DOAS is suitable for routine observations as its setup is simple, power consumption is low, and fully automated long-term operation without absolute radiometric calibration is possible. MAX-DOAS exploits characteristic features in measured spectra to retrieve both trace gas (such as nitrogen dioxide, $\mathrm{NO}_{2}$ ) and aerosol profile information for the lower troposphere (e.g., Irie et al., 2008b).

Published by Copernicus Publications on behalf of the European Geosciences Union. 
In the MAX-DOAS $\mathrm{NO}_{2}$ vertical profile retrieval, temporal changes in air mass factors (AMFs) can be taken into account by analyzing oxygen dimer $\left(\mathrm{O}_{4}\right.$ or $\left.\mathrm{O}_{2}-\mathrm{O}_{2}\right)$ absorption, which varies according to the path length of measured sunlight due mainly to changes in aerosol extinction in the lower troposphere as well as changes in the position of the Sun (e.g., Wagner et al., 2004; Frieß et al., 2006; Irie et al., 2008a). In principle, this $\mathrm{NO}_{2}$ retrieval procedure can be applied to other trace gases, where significant $\mathrm{O}_{4}$ absorption is available for both the UV and visible regions. This potential, however, has been poorly explored, as MAX-DOAS development is still at an early stage. There have been only limited studies attempting the retrieval of other trace gases, such as bromine monoxide $(\mathrm{BrO})$, sulfur dioxide $\left(\mathrm{SO}_{2}\right)$, formaldehyde (HCHO), glyoxal (CHOCHO), and water vapor $\left(\mathrm{H}_{2} \mathrm{O}\right)$ (e.g., Hönninger and Platt, 2002; Bobrowski et al., 2003; Wittrock et al., 2004; Heckel et al., 2005; Sinreich et al., 2007; Inomata et al., 2008; Takashima et al., 2009).

The Cabauw Intercomparison Campaign of Nitrogen Dioxide measuring Instruments (CINDI) was held under the auspices of the European Space Agency (ESA), the international Network for the Detection of Atmospheric Composition Change (NDACC), and the EU Framework 6's ACCENT-AT2 Network of Excellence and GEOMON Integrated Project. The campaign took place at Cabauw $\left(51.97^{\circ} \mathrm{N}, 4.93^{\circ} \mathrm{E}\right)$ at the KNMI Cabauw Experimental Site for Atmospheric Research (CAESAR), the Netherlands, in June-July 2009. Fourteen international groups participated in the CINDI campaign. The $\mathrm{NO}_{2}$ and $\mathrm{O}_{4}$ slant column densities (SCDs) retrieved from wavelength intervals of 425$490 \mathrm{~nm}$ in the visible and $338-370 \mathrm{~nm}$ in the UV have been formally intercompared according to a formal semiblind protocol defined by the NDACC (Roscoe et al., 2010), providing a basis for further interpretation of profile retrievals. Here we present and apply our newly developed multi-component profile retrieval method, called JM1 (the Japanese MAX-DOAS profile retrieval algorithm, version 1), to MAX-DOAS observations taken during CINDI. We show that MAX-DOAS can reasonably retrieve 8 components: the aerosol extinction coefficients (AECs) at two wavelengths, 357 and $476 \mathrm{~nm}$, and $\mathrm{NO}_{2}, \mathrm{HCHO}, \mathrm{CHOCHO}, \mathrm{H}_{2} \mathrm{O}, \mathrm{SO}_{2}$, and $\mathrm{O}_{3}$ volume mixing ratios (VMRs) for the layer $0-1 \mathrm{~km}$, which corresponds to the lowest layer in profiles retrieved with JM1, where the highest sensitivity is usually expected owing to the longest light path. The potential of such multicomponent retrievals is discussed using comparisons with other independent data, including a regional chemical transport model (CHIMERE) and in situ observations performed near the surface $(2-3 \mathrm{~m})$ and at $200 \mathrm{~m}$ on a tower placed in Cabauw. The potential to bridge different data sets (such as in situ and satellite observations and model calculations) having different spatial resolutions is also confirmed by analyzing air mass factors that are determined by JM1 at the same time as the aerosol retrieval.

\section{Instrumentation}

From 8 June to 24 July 2009, the JAMSTEC (Japan Agency for Marine-Earth Science and Technology) MAX-DOAS instrument was operated continuously at Cabauw, the Netherlands. It consists of a telescope unit placed outdoors and a spectrometer unit indoors. These were connected by a multimode step-index fiber. A miniaturized UV/visible spectrometer (Ocean Optics, Inc., USB4000) equipped with a 3648-element linear CCD was used to record spectra between 223 and $558 \mathrm{~nm}$. Its temperature was kept constant at $40.0 \pm 0.1{ }^{\circ} \mathrm{C}$. The wavelength calibration using a highresolution solar spectrum (Kurucz et al., 1984) indicated that the spectral resolution (Full Width at Half Maximum FWHM) was $0.76,0.71,0.66$, and $0.61 \mathrm{~nm}$ at wavelengths around $350,400,450$, and $500 \mathrm{~nm}$, respectively. The integration time was kept constant throughout the day at around $100 \mathrm{msec}$. Spectra recorded at a fixed elevation angle for a 5-min interval were averaged and analyzed. The telescope unit, directed to an azimuth angle of $287^{\circ}$ (northwest), was placed on the roof of cabin \#4 at the CAESAR remote sensing site. The field of view was $<1^{\circ}$. A single plano-convex lens (focal length $=40 \mathrm{~mm}$ and diameter $=25 \mathrm{~mm}$ ) was used to focus the received sunlight onto the fiber. The window and lens were both made of quartz. No optical coatings were made. A movable mirror (UV reflective) in the telescope unit was controlled by a PC to record spectra sequentially at six different elevation angles of $2^{\circ}, 4^{\circ}, 8^{\circ}, 15^{\circ}, 30^{\circ}$, and $90^{\circ} \mathrm{ev}-$ ery $30 \mathrm{~min}$. On $8-21$ June, an elevation angle of $3^{\circ}$ was used instead of $2^{\circ}$. Power consumption was roughly estimated to be less than 200 VA for the whole system, including the PC.

\section{Japanese MAX-DOAS profile retrieval algorithm, version 1 (JM1)}

Here we present the Japanese MAX-DOAS profile retrieval algorithm, version 1, called JM1. The JM1 algorithm can be divided into 3 steps: DOAS analysis, aerosol profile retrieval, and gas profile retrieval. Below, we describe the procedure for each step. The $\mathrm{O}_{3}$ profile retrieval method is described separately from other trace gases, since additional considerations are required for high altitudes, as discussed in detail later.

\subsection{DOAS analysis}

DOAS spectral fitting (Platt and Stutz, 2008) using the nonlinear least-squares method (Irie et al., 2008a) was performed to retrieve the differential slant column density $(\triangle \mathrm{SCD})$, which is defined as the difference between the SCD along the path of sunlight for a non-zenith measurement $\left(\mathrm{EL}<90^{\circ}\right)$ and the SCD for a zenith-sky measurement $\left(E L=90^{\circ}\right)$. The $\mathrm{SCD}$ of $\mathrm{O}_{4}$ is referred to as the integrated quadratic $\mathrm{O}_{2}$ concentration (units: molecules ${ }^{2} \mathrm{~cm}^{-5}$ ) and therefore contains the equilibrium constant between $\mathrm{O}_{4}$ and $2 \mathrm{O}_{2}$ (Greenblatt et 
Table 1. Fitting windows and absorbers fitted in DOAS analysis. The representative wavelength for each target component is its crosssection-weighted mean wavelength over the fitting window.

\begin{tabular}{lrrc}
\hline $\begin{array}{l}\text { Target } \\
\text { component }\end{array}$ & $\begin{array}{c}\text { Fitting } \\
\text { window }\end{array}$ & $\begin{array}{r}\text { Absorbers } \\
\text { fitted }\end{array}$ & $\begin{array}{r}\text { Representative } \\
\text { wavelength } \\
(\mathrm{nm})\end{array}$ \\
\hline $\mathrm{SO}_{2}$ & $310-320$ & $\mathrm{O}_{3}, \mathrm{NO}_{2}, \mathrm{HCHO}, \mathrm{SO}_{2}$, Ring & 315 \\
$\mathrm{O}_{3}$ & $310-335$ & $\mathrm{O}_{3}, \mathrm{NO}_{2}, \mathrm{HCHO}, \mathrm{SO}_{2}, \mathrm{Ring}$ & 317 \\
$\mathrm{HCHO}$ & $336-359$ & $\mathrm{O}_{3}, \mathrm{NO}_{2}, \mathrm{HCHO}, \mathrm{BrO}, \mathrm{O}_{4}$, Ring & 344 \\
$\mathrm{AEC} \mathrm{H}_{357 \mathrm{~nm}}$ & $338-370$ & $\mathrm{O}_{3}, \mathrm{NO}_{2}, \mathrm{HCHO}, \mathrm{BrO}, \mathrm{O}_{4}$, Ring & 357 \\
$\mathrm{CHOCHO}$ & $436-457$ & $\mathrm{O}_{3}, \mathrm{NO}_{2}, \mathrm{CHOCHO}_{2} \mathrm{O}, \mathrm{O}_{4}$, Ring & 448 \\
$\mathrm{NO}_{2}$ & $460-490$ & $\mathrm{O}_{3}, \mathrm{NO}_{2}, \mathrm{H}_{2} \mathrm{O}, \mathrm{O}_{4}$, Ring & 474 \\
$\mathrm{AEC}_{476 \mathrm{~nm}}$ & $460-490$ & $\mathrm{O}_{3}, \mathrm{NO}_{2}, \mathrm{H}_{2} \mathrm{O}, \mathrm{O}_{4}$, Ring & 476 \\
$\mathrm{H}_{2} \mathrm{O}$ & $495-515$ & $\mathrm{O}_{3}, \mathrm{NO}_{2}, \mathrm{H}_{2} \mathrm{O}$, Ring & 506 \\
\hline
\end{tabular}

al., 1990). The reference spectrum at the time of the nonzenith measurement was derived by interpolating two zenith spectra measured within $30 \mathrm{~min}$ before and after the nonzenith measurement. Thereby, the reference spectrum can be assumed to have been measured under the same atmospheric conditions (e.g., aerosol and $\mathrm{NO}_{2}$ profiles) as those for non-zenith observations, so that the difference should come only from a difference in elevation angle (and hence path length and AMF). In cases that rapid changes in optical depth within $30 \mathrm{~min}$ occurred, for example, due to the passage of clouds, the residuals for the aerosol profile retrieval can be larger and the cases are subject to data screening, as mentioned later. For each of the components retrieved in the present study, the fitting window used in the DOAS analysis is given in Table 1. Examples of fitting results are shown in Fig. 1. Two different fitting windows, 338-370 and $460-490 \mathrm{~nm}$, were analyzed for aerosol retrievals at 357 and $476 \mathrm{~nm}$, respectively. These wavelengths correspond to the $\mathrm{O}_{4}$-cross-section-weighted mean wavelengths for the respective fitting window. Our DOAS analysis is supported by formal semi-blind intercomparison results indicating good agreement with other MAX-DOAS observations, to within $\sim 10 \%$ of the mean values of selected instruments, for both $\mathrm{NO}_{2}$ and $\mathrm{O}_{4}$ and for both the UV and visible regions (Roscoe et al., 2010). While the CINDI semi-blind intercomparison used the window $425-490 \mathrm{~nm}$, the present study uses 460 $490 \mathrm{~nm}$ for much faster retrievals by the DOAS fitting used in JM1. Also, the difference between representative wavelengths for $\mathrm{NO}_{2}$ and $\mathrm{O}_{4}$ can be very small, minimizing the wavelength-dependence of AMF information, as mentioned later. For both $\mathrm{NO}_{2}$ and $\mathrm{O}_{4}$, correlations between $\triangle \mathrm{SCD}$ values from respective fitting windows indicated $R^{2}>0.99$, with mean differences of about $5 \%$, which is within the range of agreement found in semi-blind intercomparisons $(\sim 10 \%)$ and the range of uncertainty in $\mathrm{NO}_{2}$ VMR retrieved below. Furthermore, considering that part of the differences should be caused by the difference of AMFs at different wavelengths, the impact on the accuracy for $\triangle \mathrm{SCD}$ values should be smaller than the calculated differences.

The fitting windows of 336-359 and 338-370 nm include nitrous acid (HONO) absorption bands. We performed additional DOAS analysis with HONO for both fitting windows. By including HONO, its impact on $\mathrm{O}_{4} \Delta$ SCDs was estimated to be only $0.2 \%$, whereas HCHO $\triangle$ SCDs decreased by $9 \%$ on average for the whole observation period. However, when HONO was included, $43 \%$ of HONO $\triangle \mathrm{SCD}$ data showed negative values, potentially indicating that it could interfere with $\mathrm{HCHO}$ directly and/or indirectly through $\mathrm{O}_{3}$. Therefore, we have not included HONO in the present study.

Most of the absorption cross section data used here are the same as those used in the formal semi-blind intercomparison (Roscoe et al., 2010). For $\mathrm{H}_{2} \mathrm{O}$, we used the year 2004 edition of the High-Resolution Transmission (HITRAN) database. To account for possible $\mathrm{H}_{2} \mathrm{O}$ line saturation effects, the retrieved $\mathrm{H}_{2} \mathrm{O} \Delta \mathrm{SCD}$ values were scaled by applying a SCD-dependent scaling factor. The scaling factor, defined as the ratio of SCD retrieved from DOAS fitting to the corrected SCD, was estimated by comparing the cross sections convolved from original high-resolution cross sections with the effective cross sections derived from simulation of transmitted spectra assuming a given SCD value. For example, it is about 0.90 at a SCD of $5 \times 10^{23}$ molecules $\mathrm{cm}^{-2}$. For $\mathrm{O}_{4}$, Hermans' cross section data at $296 \mathrm{~K}$ (http://www. aeronomie.be/spectrolab/o2.htm) were used. Recently, Wagner et al. (2009) and Clémer et al. (2010) found that the retrieved $\mathrm{O}_{4}$ SCDs were systematically too high to match the model simulation even under pure Rayleigh conditions, at least at the times and locations of their MAX-DOAS observations. These differences might be induced in the DOAS retrieval by uncertainties in the absolute values of the $\mathrm{O}_{4}$ cross sections. Also, the temperature and pressure dependencies of the $\mathrm{O}_{4}$ absorption cross sections are not well known. From their observation-model comparisons, for instance, Clémer et al. (2010) derived a correction factor for the absolute value 

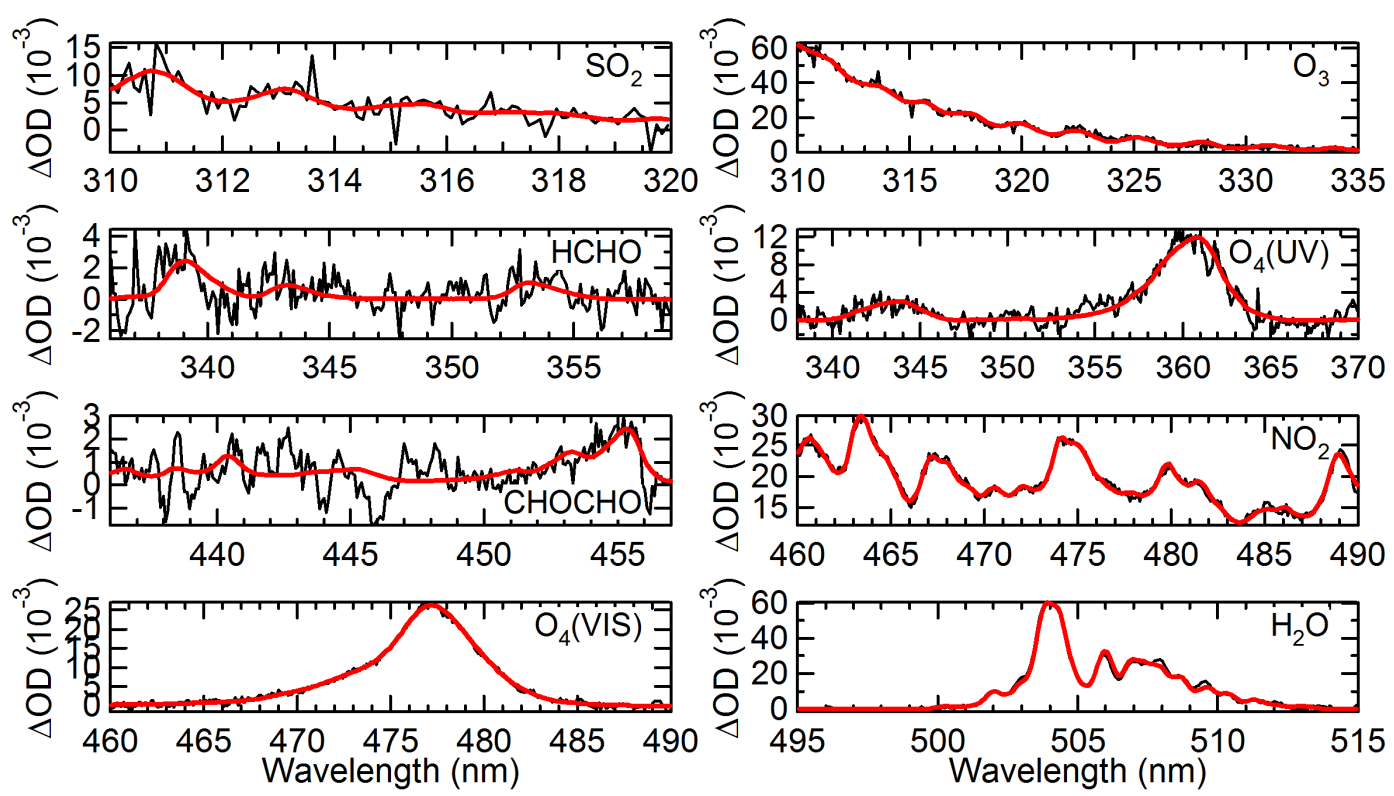

Fig. 1. Examples of fitting results for all species used for the 8-component retrievals (around 11:18 UTC on $11 \mathrm{July} 2009$; EL $=2^{\circ}$ ). These are cases showing moderate levels of $\triangle$ SCDs and fitting residuals for all species at the same time. The red lines show the cross sections scaled to the measured spectra (black) by the DOAS technique. The spectra are plotted as the differential optical density ( $\Delta$ OD) from the reference spectrum. Note that different wavelength ranges are used for the 8 panels.

of the $\mathrm{O}_{4}$ cross section of $25 \pm 10 \%$ at four different wavelengths, including around 360 and $477 \mathrm{~nm}$, for which we retrieve $\mathrm{O}_{4} \Delta \mathrm{SCD}$ in the present study. Wagner et al. (2009) estimated, with an uncertainty of about $10 \%$, the $\mathrm{O}_{4}$ cross section at $360 \mathrm{~nm}$ to be $5.27 \times 10^{-46} \mathrm{~cm}^{5}$ molecules ${ }^{-2}$, which is $23 \%$ higher than the Hermans cross section at $360 \mathrm{~nm}$ $\left(4.29 \times 10^{-46} \mathrm{~cm}^{5}\right.$ molecules $\left.^{-2}\right)$. To take into account not only this possible systematic bias of about $25 \%$ in the $\mathrm{O}_{4}$ cross sections but also part of the associated large uncertainty of $10 \%$, we implement this adjustable correction in the aerosol retrieval, as described below.

\subsection{Vertical profile retrieval method}

\subsubsection{Aerosol extinction coefficients (AECs) at 357 and $476 \mathrm{~nm}$}

AEC profiles at 357 and $476 \mathrm{~nm}$ are retrieved separately. For each wavelength, $\mathrm{O}_{4} \Delta \mathrm{SCD}$ values derived from different fitting windows, 338-370 and 460-490 nm, are used. We utilize the Optimal Estimation Method (OEM; Rodgers, 2000) to solve the nonlinear inversion problem with the iteration equation:

$$
\begin{gathered}
\boldsymbol{x}_{i+1}=\boldsymbol{x}_{i}+\left(\mathbf{S}_{\mathrm{a}}^{-1}+\mathbf{K}_{i}^{T} \mathbf{S}_{\varepsilon}^{-1} \mathbf{K}_{i}+\gamma_{i} \mathbf{D}\right)^{-1} \\
\left\{\mathbf{K}_{i}^{T} \mathbf{S}_{\varepsilon}^{-1}\left[\boldsymbol{y}-F\left(\boldsymbol{x}_{i}\right)\right]-\mathbf{S}_{\mathrm{a}}^{-1}\left[\boldsymbol{x}_{i}-\boldsymbol{x}_{\mathrm{a}}\right]\right\}
\end{gathered}
$$

where $\boldsymbol{x}_{i+1}$ and $\boldsymbol{x}_{i}$ are the current and previous state vectors, respectively. $\mathbf{S}_{\varepsilon}$ is the measurement error covariance matrix,
$\mathbf{K}_{i}$ is the weighting function matrix (in which each element is the partial derivative of a measurement vector component over a state vector), and $\mathbf{F}$ represents the forward model converting given aerosol profile information to $\mathrm{O}_{4} \Delta S C D$ values. $\mathbf{D}$ is a diagonal scaling matrix for numerical efficiency, and $\gamma_{i}$ is a parameter updated each iteration to optimize the retrieval. $\boldsymbol{x}_{a}$ and $\mathbf{S}_{a}$ are the a priori state vector and the a priori covariance matrix, respectively.

For each wavelength, the measurement vector $(y$; representing the quantities to be fitted) and the state vector ( $x$; representing the quantities to be retrieved) are defined as

$\boldsymbol{y}=\left(\mathrm{O}_{4} \Delta \mathrm{SCD}\left(\Omega_{1}\right) \cdots \mathrm{O}_{4} \Delta \operatorname{SCD}\left(\Omega_{n}\right)\right)^{T}$

and

$\boldsymbol{x}=\left(\begin{array}{lllll}\mathrm{AOD} & F_{1} & F_{2} & F_{3} & f_{\mathrm{O} 4}\end{array}\right)^{T}$,

respectively, where $n$ is the number of measurements in a 30 -min interval, which corresponds to a complete scan for a set of ELs, and $\Omega$ is the observation geometry vector consisting of three components: the solar zenith angle (SZA), relative azimuth angle (RAA), and EL. RAA is the azimuth angle between the telescope direction and the Sun. $F$ values are the parameters determining the shape of the vertical profile and are defined to range between 0 and 1 . Thereby, we describe partial AOD values for $0-1,1-2$, and $2-3 \mathrm{~km}$ as $\mathrm{AOD} \cdot F_{1}$, AOD $\cdot\left(1-F_{1}\right) F_{2}$, and $\mathrm{AOD} \cdot\left(1-F_{1}\right)\left(1-F_{2}\right) F_{3}$, respectively, and the partial AOD above $3 \mathrm{~km}$ as AOD (1$\left.F_{1}\right)\left(1-F_{2}\right)\left(1-F_{3}\right)$. From a given partial AOD above $3 \mathrm{~km}$, we determine the profile of AEC for the layer from 3 to $100 \mathrm{~km}$ 
assuming an AEC value at the top of the layer $(100 \mathrm{~km})$ and an exponential profile shape. Similarly, we determine profiles for layers of 2-3,1-2, and 0-1 km, completing the AEC vertical profile from the surface up to $100 \mathrm{~km}$ (Irie et al., 2008a).

This parameterization has an advantage that the retrieval can be made without a priori knowledge of the absolute value of the AEC in the troposphere. Instead, a priori knowledge of the profile shape (represented by the $F$ values) is needed, but in our previous work (Irie et al., 2008a) the relative variability of the profile shape, in terms of 1-km averages (i.e., $F$ values), was much smaller than that of the absolute AEC value. On the other hand, there are disadvantages in that the vertical resolution and the measurement sensitivity cannot readily be derived (Irie et al., 2008a, 2009). To account for this, we relied on simulations for similar geometries (e.g., Frieß et al., 2006), comparisons with other data, such as lidar measurements, and analysis of air mass factors (i.e., Irie et al., 2008a, 2009).

The $f_{O 4}$ value is the scaling factor for $\mathrm{O}_{4} \triangle \mathrm{SCD}$ values calculated by the forward model. This factor is included to compensate for a possible bias in $\mathrm{O}_{4} \Delta \mathrm{SCD}$ values derived from DOAS fitting due to a bias in $\mathrm{O}_{4}$ cross section data. For example, if the original $\mathrm{O}_{4}$ cross section is smaller than the true value by $25 \%$, the $\triangle \mathrm{SCD}$ values derived from the DOAS fit should be systematically larger than the true $\triangle \mathrm{SCD}$ values, leading to a discrepancy with $\triangle \mathrm{SCD}$ values calculated by the forward model. To minimize this effect, $\triangle \mathrm{SCD}$ values derived from the DOAS fit were kept unchanged but the scaling factor $f_{O 4}$ was introduced. In this case, a negative bias in cross sections of $25 \%$ simply corresponds to a $f_{O 4}$ of 1.25. Also, including $f_{O 4}$ in the state vector allows the bias in the cross sections to vary with time, enabling one to account for part of the uncertainty in $\mathrm{O}_{4}$ cross sections possibly caused by changes in temperature and pressure in the lower troposphere.

A lookup table (LUT) of the box-air-mass-factor $\left(A_{\text {box }}\right)$ vertical profile, which was used to calculate $\mathrm{O}_{4} \Delta \mathrm{SCD}$ from given aerosol profiles and observation geometries in the forward model, was created using our radiative transfer model, the Monte Carlo Atmospheric Radiative Transfer Simulator (MCARaTS) (Iwabuchi, 2006). The $A_{\text {box }}$ calculations by MCARaTS have been validated through comparisons with other radiative transfer models (Wagner et al., 2007). To simulate a realistic atmosphere, we considered the surface altitude at the measurement site and the altitude where the instrument was located. Different LUTs were prepared for two wavelengths, 357 and $476 \mathrm{~nm}$. We assumed single values of the single scattering albedo $(s=0.95)$, asymmetry parameter ( $g=0.65$, under the Henyey-Greenstein approximation), and surface albedo $(a=0.10)$. The sensitivities of the AEC retrievals to changing these parameters $(g, s$, and $a$ ) by \pm 0.05 were estimated to be less than $8 \%, 1 \%$, and $2 \%$, respectively (Irie et al., 2008a).
For non-zenith measurement geometries, we also created a LUT for profiles of $\Delta A_{\text {box }}$, which was calculated by subtracting the corresponding zenith-sky $A_{\text {box }}$ value. Instead of $A_{\text {box }}$, the $\Delta A_{\text {box }}$ value was used in the retrieval, as it is more directly linked to $\triangle \mathrm{SCD}$.

We used a priori values ( \pm error) that have been slightly modified from those used in our previous work (Irie et al., 2008a, 2009). The values used in the present work were AOD $(357 \mathrm{~nm})=0.28 \pm 3.0, \quad$ AOD $(476 \mathrm{~nm})=0.21 \pm 3.0$, $F_{1}=0.60 \pm 0.05, \quad F_{2}=0.80 \pm 0.03$, and $F_{3}=0.80 \pm 0.03$. These correspond to AEC $(357 \mathrm{~nm})=0.17 \mathrm{~km}^{-1}$ and AEC $(476 \mathrm{~nm})=0.13 \mathrm{~km}^{-1}$ as mean values for the $0-1 \mathrm{~km}$ layer. The errors are $+1.96 /-1.94 \mathrm{~km}^{-1}$ and $+2.22 /-1.94 \mathrm{~km}^{-1}$, respectively, allowing wide ranges of AEC values to be retrieved. According to the results of Clémer et al. (2010), the a priori value for $f_{O 4}$ was set to $1.25 \pm 0.02$, where the error of 0.02 was chosen for the retrieved $f_{O 4}$ in order to account for a typical range of \pm 0.10 for the entire campaign period. Non-diagonal elements of the a priori covariance matrix were set to zero.

To characterize the retrieval, the averaging kernel was analyzed. For all data presented in this study, the mean value ( $\pm 1 \sigma$ standard deviation) of the degrees of freedom for signal (DFS; Rodgers, 2000) was calculated to be about $2.1 \pm 0.6$ for both wavelengths. The area (Rodgers, 2000) that provides a rough measure of the fraction of the retrieval that comes from the measurements was calculated as the sum of all elements in the averaging kernel profile weighted by the a priori error (Liu et al., 2005). The areas were 1.0, 0.5, and 0.2 for AOD, $F_{1}$, and $f_{O 4}$, respectively. Much smaller values $(<0.1)$ were found for $F_{2}$ and $F_{3}$. These indicate that the retrieval was done by scaling the given a priori profile first, followed by changing the profile shape mainly by $F_{1}$. The scaling factor $f_{O 4}$ is constrained by the a priori rather than the measurements, but including $f_{O 4}$ increases DFS owing to improved agreement between $\triangle \mathrm{SCD}$ values derived from the DOAS fit and the forward model.

The error of the retrieved state vector is quantified by the retrieval covariance matrix,

$\hat{\mathbf{S}}=\left(\mathbf{K}^{T} \mathbf{S}_{\varepsilon}^{-1} \mathbf{K}+\mathbf{S}_{a}^{-1}\right)^{-1}$,

which is defined to represent the sum of the smoothing error and the retrieval noise error (Rodgers, 2000). For this error estimate, the measurement error covariance matrix $\mathbf{S}_{\varepsilon}$ was constructed from the residual of $\mathrm{O}_{4} \Delta \mathrm{SCD}$, because it was usually larger than the $\mathrm{O}_{4} \Delta \mathrm{SCD}$ errors. The random error, assumed to be given by $\mathbf{S}$, was estimated for each retrieval. Median values of the estimated random errors for all retrievals were $0.03 \mathrm{~km}^{-1}(13 \%)$ and $0.02 \mathrm{~km}^{-1}(10 \%)$ for AECs at 357 and $476 \mathrm{~nm}$, respectively (Table 1). For both wavelengths, mean differences from AECs retrieved with $f_{O 4}$ fixed at 1.25 were $0.00 \pm 0.02 \mathrm{~km}^{-1}(0 \pm 8 \%)$ for the entire period. There are several sources leading to systematic errors, but the total errors containing such systematic 
components of the errors are likely smaller than $50 \%$ and $30 \%$, respectively, according to our previous comparisons with lidar and sky radiometer measurements (Irie et al., 2008a, 2009).

It is known that clouds can bias the retrieved AECs. While the discrimination between clouds and aerosols is still very challenging, the following data screenings were made to minimize the influence of clouds. First, we filtered output from the retrieval only for retrieved AOD less than 3, the largest value in the LUTs. This excludes large optical depth cases, most of which should be due to optically thick clouds. Further data screening was made using the root-mean squares of residuals of the $\mathrm{O}_{4} \Delta \mathrm{SCD}$ values. Larger residuals likely occurred when the above-mentioned method constructing a profile was too simple to represent the true profile, particularly with a steep vertical gradient of extinction due to clouds. Also, rapid changes in optical depth within 30 min that corresponds to the full scanning time can lead to larger residuals. The threshold for this data screening was set to $15 \%$ of the mean $\mathrm{O}_{4} \Delta \mathrm{SCD}$ in each 30-min interval. While the complete data set is expected to have 1159 AEC profiles for each wavelength, we obtained $555(48 \%)$ and $625(54 \%)$ profiles at 357 and $476 \mathrm{~nm}$, respectively, after these data screenings.

Typical vertical profiles of AECs at 357 and $476 \mathrm{~nm}$ retrieved by JM1 are shown in Fig. 2. For the 0-1 km layer, median values during the observation period were found to be 0.24 and $0.18 \mathrm{~km}^{-1}$ at 357 and $476 \mathrm{~nm}$, respectively (Fig. 2 and Table 1). Using these values, the Ångström exponent was estimated to be 1.00, which is not for AOD but AECs in the layer below $1 \mathrm{~km}$.

\subsubsection{Trace gases except ozone}

For trace gases $\mathrm{NO}_{2}, \mathrm{HCHO}, \mathrm{CHOCHO}, \mathrm{H}_{2} \mathrm{O}$, and $\mathrm{SO}_{2}$, we use a method similar to the aerosol retrieval described above. Below, we explain the retrieval algorithm primarily for $\mathrm{NO}_{2}$. For the other trace gases, the same procedure is followed unless otherwise mentioned. We utilize OEM, where the measurement vector and the state vector are defined as

$\boldsymbol{y}=\left(\mathrm{NO}_{2} \Delta \mathrm{SCD}\left(\Omega_{1}\right) \cdots \mathrm{NO}_{2} \Delta \mathrm{SCD}\left(\Omega_{n}\right)\right)^{T}$

and

$\boldsymbol{x}=\left(\begin{array}{llll}\mathrm{VCD} & F_{1} & F_{2} & F_{3}\end{array}\right)^{T}$,

respectively, where VCD is defined as the vertical column density for altitudes below $5 \mathrm{~km}\left(8 \mathrm{~km}\right.$ for $\left.\mathrm{H}_{2} \mathrm{O}\right)$. Above this height, fixed profiles are assumed. For example, number densities of $\mathrm{NO}_{2}$ have been fixed at $0.3,0.1,7.6,21.1$, and $2.5 \times 10^{8}$ molecules $\mathrm{cm}^{-3}$ at $5,10,20,30$, and $40 \mathrm{~km}$, respectively. These values are mostly based on data from the Halogen Occultation Experiment (HALOE) at midlatitudes. Similarly, for $\mathrm{HCHO}, \mathrm{CHOCHO}, \mathrm{H}_{2} \mathrm{O}$, and $\mathrm{SO}_{2}$, number densities at $5 \mathrm{~km}\left(8 \mathrm{~km}\right.$ for $\left.\mathrm{H}_{2} \mathrm{O}\right)$ have been assumed to be $1.2 \times 10^{8}, 1.2 \times 10^{6}, 1.8 \times 10^{16}$, and $4.0 \times 10^{7}$ molecules
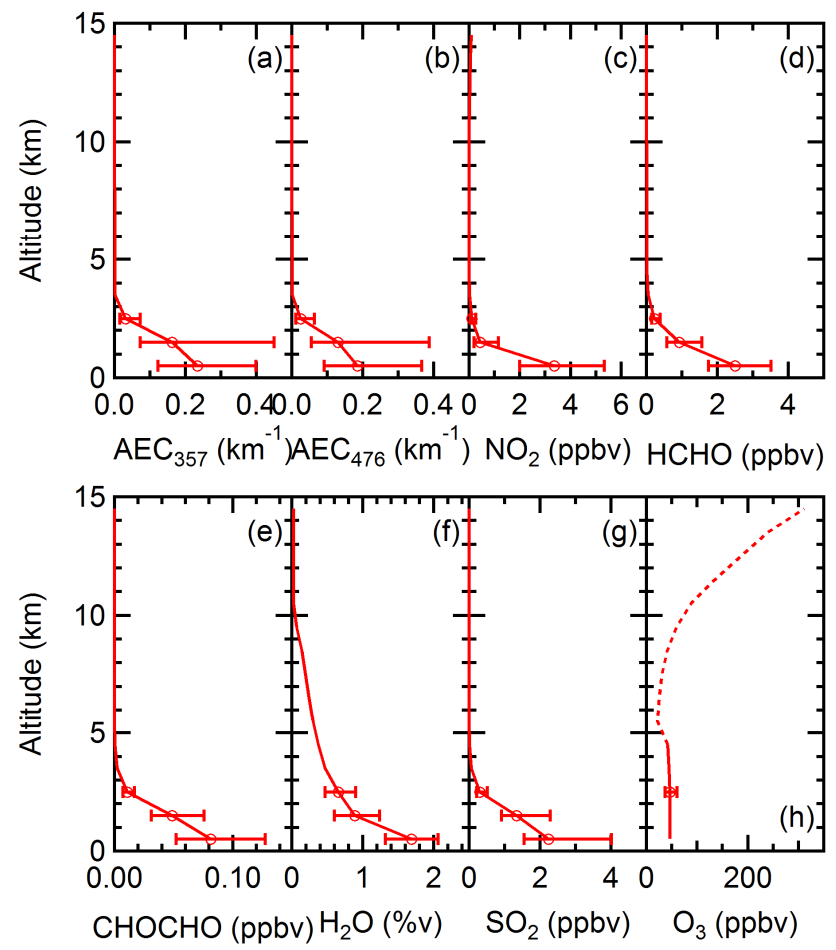

Fig. 2. Median vertical profiles of AECs at 357 and $476 \mathrm{~nm}$ and $\mathrm{NO}_{2}, \mathrm{HCHO}, \mathrm{CHOCHO}, \mathrm{H}_{2} \mathrm{O}, \mathrm{SO}_{2}$, and $\mathrm{O}_{3}$ VMRs retrieved for the CINDI campaign period. Error bars represent the $67 \%$-range. For all species except $\mathrm{O}_{3}$, vertical profiles above $3 \mathrm{~km}$ have been determined mostly by the a priori. For $\mathrm{O}_{3}$, two different parameters retrieved represent $\mathrm{O}_{3}$ vertical profiles below (solid curve) and above $5 \mathrm{~km}$ (dotted curve), respectively (see the text for more details).

$\mathrm{cm}^{-3}$, respectively. For $\mathrm{HCHO}$ and $\mathrm{H}_{2} \mathrm{O}$, certain profiles are also assumed above this height. These assumptions might be crude, but their impact on the results is very minor; the sensitivity of the retrieval of VMRs at $0-1 \mathrm{~km}$ to doubled concentrations above $5 \mathrm{~km}\left(8 \mathrm{~km}\right.$ for $\left.\mathrm{H}_{2} \mathrm{O}\right)$ was estimated, by comparing VMRs retrieved using the original and doubled concentrations, to be less than $0.3 \%$ for all these trace gases.

The vertical profile below $5 \mathrm{~km}\left(8 \mathrm{~km}\right.$ for $\left.\mathrm{H}_{2} \mathrm{O}\right)$ is represented by VCD and $F$ values after these values are converted to partial VCD values for $0-1,1-2,2-3$, and $3-5 \mathrm{~km}(3-8 \mathrm{~km}$ for $\mathrm{H}_{2} \mathrm{O}$ ), as done in the aerosol retrievals above. Note that the resulting partial $\mathrm{VCD}$ values, such as $\mathrm{VCD} \cdot F_{1}$ for the $0-1 \mathrm{~km}$ layer, gives a mean number density (VCD $F_{1} \cdot \Delta z$, where $\Delta z=1 \mathrm{~km}$ ) for a given $1-\mathrm{km}$ layer. This value is converted to VMR using US Standard Atmosphere temperature and pressure data, which are scaled to match the surface values recorded at the location and time of the measurements.

In the forward model, the calculated vertical profile is converted to $\triangle \mathrm{SCD}$ values using $\mathrm{AMF}$ information given as $\Delta A_{\text {box }}$ profiles determined in advance by the aerosol retrieval. However, there should be differences between $\Delta A_{\text {box }}$ profiles between representative wavelengths for aerosols 
(357 and $476 \mathrm{~nm}$ ) and trace gases (Table 1). To minimize this wavelength-dependence of AMF information, the AOD at the desired trace gas wavelength is estimated by converting the retrieved AOD at the closer aerosol wavelength, assuming an Ångström exponent of 1.00. Then, the $\Delta A_{\text {box }}$ profiles that correspond to the converted AOD (but at the same wavelength as the aerosol retrieval) are re-calculated from the $\Delta A_{\text {box }}$ LUT prepared for aerosol retrievals and used for trace gas retrievals. The dependence of $\Delta A_{\text {box }}$ on the concentration profile of trace gases has been omitted, since it should be small, as they are optically thin absorbers (the optical depth $<<1$ ) (Wagner et al., 2007).

Similar to the aerosol retrievals, we also try not to make any assumption of the absolute value of the concentration level in the gas retrieval. For this, the a priori for VCD is taken from internal information, namely from $\mathrm{NO}_{2} \Delta \mathrm{SCD}$. For each 30-min interval, $20 \%$ of the maximum $\mathrm{NO}_{2} \Delta \mathrm{SCD}$ values is used as the a priori VCD value. The ratio of $20 \%$ roughly corresponds to the mean ratios of the resulting retrieved VCD to maximum $\triangle \mathrm{SCD}$ values: $15 \%\left(\mathrm{NO}_{2}\right), 16 \%$ (CHOCHO), $18 \%(\mathrm{HCHO}), 19 \%\left(\mathrm{SO}_{2}\right)$, and $31 \%\left(\mathrm{H}_{2} \mathrm{O}\right)$. This idea comes from the fact that a $\triangle \mathrm{SCD}$ value can be used as a measure of the concentration level because it already contains such information. To take a wide range of values, the a priori error for VCD has been set in this work to $100 \%$ of the maximum $\triangle \mathrm{SCD}$ values. As a result, the retrieved VCD has become independent of the a priori, as the area calculated from the averaging kernels is close to unity.

For the profile-shape-determining factors $F_{1}, F_{2}$, and $F_{3}$, we simply use the same a priori as those used for the aerosol retrievals: $\quad F_{1}=0.60 \pm 0.05, \quad F_{2}=0.80 \pm 0.03$, and $F_{3}=0.80 \pm 0.03$. For $\mathrm{H}_{2} \mathrm{O}, \quad F_{1}=0.35 \pm 0.05$, $F_{2}=0.35 \pm 0.03$, and $F_{3}=0.35 \pm 0.03$ are used to represent a vertical profile with significant amounts of $\mathrm{H}_{2} \mathrm{O}$ at higher altitudes. This setup may be too simplistic, but it could easily be adjusted if better a priori knowledge was available.

The mean values of DFS for the whole period were calculated to be 1.3-1.4 for $\mathrm{NO}_{2}, \mathrm{HCHO}, \mathrm{CHOCHO}$, and $\mathrm{SO}_{2}$. Of these four components, the highest DFS was found for $\mathrm{NO}_{2}$, as expected. The $1 \sigma$ standard deviation was about $0.2-0.3$. These statistics were calculated for data that met the data screening criteria with a $\triangle \mathrm{SCD}$ residual $<20 \%$ and a DFS $>1$. The resulting numbers of profiles retrieved $(N)$ were about 600, 300, 200, and 100 for $\mathrm{NO}_{2}, \mathrm{HCHO}$, $\mathrm{CHOCHO}$, and $\mathrm{SO}_{2}$, respectively. For $\mathrm{H}_{2} \mathrm{O}$, the mean DFS was $2.0 \pm 0.3$ for all data that satisfied the above criteria $(N \sim 600)$. Compared to $\mathrm{NO}_{2}$, the DFS for $\mathrm{H}_{2} \mathrm{O}$ retrievals is significantly higher, which probably results from the fact that the maximum differential optical depth $(\Delta \mathrm{OD})$ of $\mathrm{H}_{2} \mathrm{O}$ in a DOAS fit is usually higher; for example, at $\mathrm{EL}=3^{\circ}$ and $\mathrm{SZA}<50^{\circ}, \triangle \mathrm{OD}\left(\mathrm{H}_{2} \mathrm{O}\right)$ usually reaches $\sim 0.06$, while $\Delta \mathrm{OD}\left(\mathrm{NO}_{2}\right)$ reaches $\sim 0.03$. For all these trace gases, the areas were 1.0 and $0.3-0.4\left(0.7\right.$ for $\left.\mathrm{H}_{2} \mathrm{O}\right)$ for VCD and $F_{1}$, respectively. Values for $F_{2}$ and $F_{3}$ were very small $(<\sim 0.1)$.
Thus, the retrieval has been performed mainly by scaling the given a priori profile, similar to the aerosol retrievals.

Table 2 summarizes the median values of the random and systematic errors, which were estimated in the following manner. The random error was assumed to be given by the measurement error covariance matrix $\hat{\mathbf{S}}$ defined by Eq. (4), similar to the aerosol retrievals. The systematic error was estimated assuming that it was dominated by uncertainty in the aerosol retrievals (and thus AMF determinations) (Irie et al., 2008b). For this estimate, we varied the AOD by an additional $\pm 30 \%$ for the visible products $\left(\mathrm{NO}_{2}, \mathrm{CHOCHO}\right.$, and $\mathrm{H}_{2} \mathrm{O}$ ) and by $\pm 50 \%$ for the UV products (HCHO and $\mathrm{SO}_{2}$ ), according to the uncertainties in the aerosol retrievals, as mentioned above. These can lead to a change in $\Delta A_{\text {box }}$ around $\sim 0.5 \mathrm{~km}$ by more than $30 \%$, depending on the absolute value of the AOD, the profile shape of the AEC, and the Sun position. Note that the error due to the AOD variation should include the impact of assumptions of the single scattering albedo, asymmetry parameter, and surface albedo (Irie et al., 2008a). However, there may be other significant sources of errors, such as uncertainty that arises from the lack of consideration of the temperature dependency of the $\mathrm{NO}_{2}$ cross section in DOAS fitting. This study uses $\mathrm{NO}_{2}$ cross sections measured at $298 \mathrm{~K}$ for the whole campaign period. We will address these issues in separate papers focusing on specific trace gases for more quantitative analysis.

Typical vertical profiles retrieved by JM1 during the CINDI campaign are shown in Fig. 2. For the $0-1 \mathrm{~km}$ layer, median values for $\mathrm{NO}_{2}, \mathrm{HCHO}, \mathrm{CHOCHO}, \mathrm{H}_{2} \mathrm{O}$, and $\mathrm{SO}_{2}$ VMRs were $3.4 \mathrm{ppbv}, 2.5 \mathrm{ppbv}, 81 \mathrm{pptv}, 1.7 \% \mathrm{v}$, and 2.3 ppbv, respectively (Fig. 2 and Table 1). It is interesting to note that the vertical profile gradient of $\mathrm{NO}_{2}$ is slightly steeper than those for $\mathrm{HCHO}, \mathrm{CHOCHO}$, and $\mathrm{SO}_{2}$, which are almost identical to those determined by the given a priori $F$ values. An a priori $F_{1}$ of 0.6 means that $60 \%$ of the VCD is below $1 \mathrm{~km}$. Therefore, this median profile of $\mathrm{NO}_{2}$ indicates that the fraction of VCD below $1 \mathrm{~km}$ was usually larger than $60 \%$, reflecting a strong source near the surface and a short chemical lifetime. Also, it can be seen that AEC profiles were enhanced at $1-2 \mathrm{~km}$ compared to the a priori profile shape, probably indicating that the growth of aerosols due to increasing uptake of water towards the top of the PBL persistently occurred over Cabauw.

\subsubsection{Ozone}

As mentioned above, aerosols and trace gases except $\mathrm{O}_{3}$ have been treated as if their concentrations are primarily in the lower troposphere, where the $\Delta A_{\text {box }}$ is also high. For $\mathrm{O}_{3}$, however, a different treatment should be used, since significant amounts are present at higher altitudes, as discussed below.

In Figs. 3 and 4, a typical vertical profile of ozone number density is shown together with profiles of $\Delta A_{\text {box }}$ and $\left[\mathrm{O}_{3}\right] \cdot \Delta A_{\text {box }}$ for different SZAs of $75^{\circ}$ and $35^{\circ}$, respectively, 
Table 2. Median values of retrieved quantities (AECs and VMRs in the $0-1 \mathrm{~km}$ layer) and estimated errors for the CINDI campaign period.

\begin{tabular}{lrrrr}
\hline Component & AEC or VMR & Random error $^{\mathrm{a}}$ & Systematic error & Total error $^{\mathrm{c}}$ \\
\hline $\mathrm{AEC}_{357 \mathrm{~nm}}$ & $0.24 \mathrm{~km}^{-1}$ & $0.03 \mathrm{~km}^{-1}(13 \%)$ & $<50 \% \mathrm{~d}$ & $<50 \%{ }^{\mathrm{d}}$ \\
$\mathrm{AEC}_{476 \mathrm{~nm}}$ & $0.18 \mathrm{~km}^{-1}$ & $0.02 \mathrm{~km}^{-1}(11 \%)$ & $<30 \% \mathrm{~d}$ & $<30 \%{ }^{\mathrm{d}}$ \\
$\mathrm{NO}_{2}$ & $3.4 \mathrm{ppbv}$ & $0.3 \mathrm{ppbv}(9 \%)$ & $0.4 \mathrm{ppbv}(12 \%)$ & $0.5 \mathrm{ppbv}(15 \%)$ \\
$\mathrm{HCHO}$ & $2.5 \mathrm{ppbv}$ & $0.3 \mathrm{ppbv}(12 \%)$ & $0.4 \mathrm{ppbv}(16 \%)$ & $0.6 \mathrm{ppbv}(24 \%)$ \\
$\mathrm{CHOCHO}$ & $81 \mathrm{pptv}$ & $12 \mathrm{pptv}(15 \%)$ & $9 \mathrm{pptv}(11 \%)$ & $15 \mathrm{pptv}(19 \%)$ \\
$\mathrm{H}_{2} \mathrm{O}$ & $1.7 \% \mathrm{v}^{\mathrm{e}}$ & $0.2 \% \mathrm{v}^{\mathrm{e}}(12 \%)$ & $0.3 \% \mathrm{v}^{\mathrm{e}}(18 \%)$ & $0.3 \% \mathrm{v}^{\mathrm{e}}(18 \%)$ \\
$\mathrm{SO}_{2}$ & $2.3 \mathrm{ppbv}$ & $0.4 \mathrm{ppbv}(17 \%)$ & $0.5 \mathrm{ppbv}(22 \%)$ & $0.6 \mathrm{ppbv}(26 \%)$ \\
$\mathrm{O}_{3}$ & $46 \mathrm{ppbv}$ & $1 \mathrm{ppbv}(2 \%)$ & $12 \mathrm{ppbv}(26 \%)$ & $12 \mathrm{ppbv}(26 \%)$ \\
\hline
\end{tabular}

${ }^{a}$ Assumed to be the sum of the smoothing error and the retrieval noise error. ${ }^{b}$ Assumed to be dominated by uncertainty in the aerosol retrievals (and AMF determinations) for trace gas retrievals. ${ }^{c}$ Calculated as the root-sum squares of random and systematic errors for trace gas retrievals. ${ }^{\mathrm{d}}$ Estimated by Irie et al. (2009). ${ }^{\mathrm{e}} \%$ by volume.

where $\Delta A_{\text {box }}$ values are for the wavelength $357 \mathrm{~nm}$. For $\triangle A_{\text {box }}$ calculations, we assumed that the AEC profile decreased exponentially with height and the AOD was 0.2 . The resulting AEC values at 0,1 , and $3 \mathrm{~km}$ are $\sim 0.43, \sim 0.02$ and $\sim 0.01 \mathrm{~km}^{-1}$, respectively. It can be seen that $\Delta A_{\text {box }}$ values are very small at high altitudes, particularly in the stratosphere, as expected. However, when we weight $\Delta A_{\text {box }}$ values by ozone number density $\left(\left[\mathrm{O}_{3}\right] \cdot \Delta A_{\text {box }}\right)$, it is obvious that ozone at high altitudes contributes significantly to the $\triangle \mathrm{SCD}$, which can also be defined by the integration of $\left[\mathrm{O}_{3}\right] \cdot \Delta A_{\text {box }}$ over altitude. This contribution can differ significantly under different SZA conditions, as seen by comparing the two $\left[\mathrm{O}_{3}\right] \cdot \Delta A_{\text {box }}$ profiles at different $\mathrm{SZAs}$ of $75^{\circ}$ and $35^{\circ}$ (Figs. 3 and 4$)$.

To take this effect into account but maintain similar methods for the other trace gas retrievals, we define the measurement vector and the state vector as follows:

$\boldsymbol{y}=\left(\mathrm{O}_{3} \Delta \operatorname{SCD}\left(\Omega_{1}\right) \cdots \mathrm{O}_{3} \Delta \operatorname{SCD}\left(\Omega_{n}\right)\right)^{T}$

$\boldsymbol{x}=\left(\operatorname{VCD} f_{\mathrm{clm}}\right)^{T}$,

respectively, where VCD is defined as the vertical column density for altitudes below $5 \mathrm{~km}$. We assumed that the $\mathrm{O}_{3}$ number density was $5.8 \times 10^{11}$ molecules $\mathrm{cm}^{-3}$ at $5 \mathrm{~km}$ based on the US Standard Atmosphere data and that the vertical profile shape was linear between 0 and $5 \mathrm{~km}$. Then, the vertical profile of $\mathrm{O}_{3}$ below $5 \mathrm{~km}$ was determined depending on VCD; a smaller VCD tends to yield a linearly increasing profile with altitude and a larger VCD produces a linearly decreasing profile. In this case, we implicitly assume that ozone concentrations are more variable in the PBL than in the lower free troposphere, as the primary target of this study is to see variations in concentrations in the PBL. Above $5 \mathrm{~km}$, the a priori profile has been set to the US Standard Atmosphere ozone profile. However, the given profile above $5 \mathrm{~km}$ has been made multipliable by a factor, $f_{\mathrm{clm}}$, in the retrieval. For example, the profile above $5 \mathrm{~km}$ is simply doubled at $f_{\mathrm{clm}}=2$.

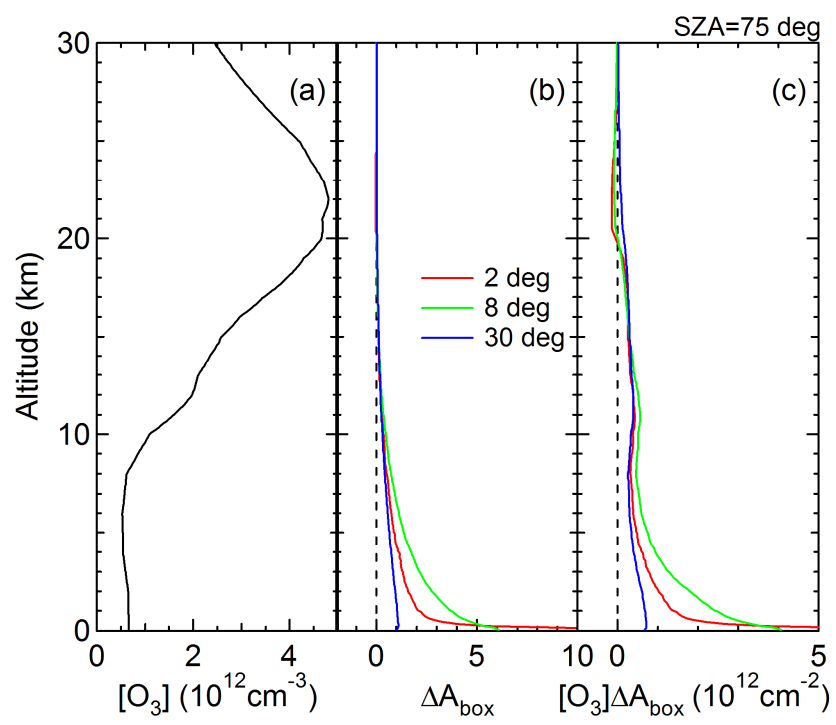

Fig. 3. Vertical profiles of (a) the number density of ozone $\left(\left[\mathrm{O}_{3}\right]\right)$ taken from the US Standard Atmosphere, (b) the differential box air mass factor $\left(\Delta A_{\text {box }}\right)$, and (c) $\left[\mathrm{O}_{3}\right] \Delta A_{\text {box }}$ at $\mathrm{SZA}=75^{\circ}$. Red, green, and blue represent elevation angles of $2^{\circ}, 8^{\circ}$, and $30^{\circ}$, respectively. Values are plotted for each $100 \mathrm{~m}$. The relative viewing azimuth angle with respect to the Sun is assumed to be $180^{\circ}$.

For each 30-min interval, $20 \%$ of the maximum $\mathrm{O}_{3} \Delta \mathrm{SCD}$ values was used as the a priori VCD value. Similar to other trace gas retrievals, the a priori error for VCD has been set to $100 \%$ of the maximum $\triangle \mathrm{SCD}$ values for each 30 -min scan time. The a priori $f_{\text {clm }}$ ( \pm error) was set to $1.0 \pm 1.0$. Note that as the a priori errors for both VCD and $f_{\text {clm }}$ were large, almost all information for the retrieval of $\mathrm{O}_{3}$ comes from the measurements; the mean DFS for all measurements was 1.997 and the areas were both almost unity. This implies that putting more parameters into the state vector would improve the retrieval performance.

Error estimates were performed in the same manner as for the other trace gases. The estimated random and systematic 


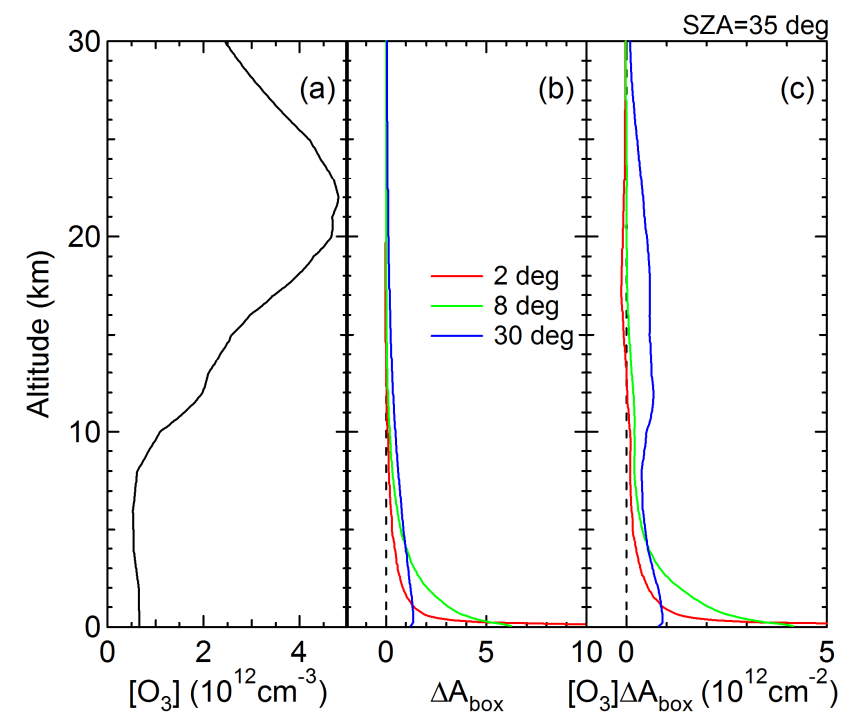

Fig. 4. Same as Fig. 3 but for $\mathrm{SZA}=35^{\circ}$.

errors were $1 \mathrm{ppbv}(2 \%)$ and $12 \mathrm{ppbv}(26 \%)$, respectively (Table 1). Retrievals with fixed $f_{\text {clm }}=1$ yielded $\mathrm{O}_{3}$ VMRs smaller by $9 \pm 7 \mathrm{ppbv}(20 \pm 15 \%)$, confirming the importance of the correction for $\mathrm{O}_{3}$ above $5 \mathrm{~km}$. Because the contribution of upper-troposphere/lower-stratosphere ozone to the $\triangle$ SCDs at low ELs tends to be higher at higher SZAs (Figs. 3 and 4), we screened-out such cases using a threshold of $\mathrm{SZA}=50^{\circ}$. A typical vertical profile of $\mathrm{O}_{3}$ retrieved by JM1 is shown in Fig. 2. The median value for $\mathrm{O}_{3}$ VMR at $0-1 \mathrm{~km}$ was 46 ppbv (Fig. 2 and Table 1).

\section{CHIMERE}

The CHIMERE offline, regional chemistry transport model (CTM) v200606A (http://www.lmd.polytechnique.fr/ chimere/) is driven by assimilated meteorological data from the European Centre for Medium-Range Weather Forecasts (ECMWF). The ECMWF dataset is given on 91 atmospheric layers at a horizontal resolution of $0.5^{\circ} \times 0.25^{\circ}$ (longitude/latitude) and has a temporal resolution of $6 \mathrm{~h}$ ( $3 \mathrm{~h}$ for surface variables and mixing depths). We interpolate the horizontal resolution to $0.5^{\circ} \times 0.5^{\circ}$ and 8 hybrid sigma pressure levels up to $500 \mathrm{hPa}$ in the vertical for input to CHIMERE. The domain of the model is centered at $45^{\circ} \mathrm{N}, 10^{\circ} \mathrm{E}$ and spans approximately $300 \times 300 \mathrm{~km}^{2}$, covering the entire European continent. Transport, vertical diffusion, dry deposition, below-cloud scavenging, and $\mathrm{SO}_{2}$ oxidation in clouds are included in the model (see Table 3). We use European anthropogenic emissions from Visschedijk et al. (2007) at high spatial resolution $\left(1 / 8^{\circ} \times 1 / 16^{\circ}\right.$ longitude/latitude) for the year 2003. The total amount of anthropogenic $\mathrm{NO}_{\mathrm{x}}$ emissions for the European domain is $4.2 \mathrm{Tg} \mathrm{N} \mathrm{yr}^{-1}$. CHIMERE does not include $\mathrm{NO}_{\mathrm{x}}$ produced by lightning or aircraft in the
Table 3. Overview of meteorological processes included in CHIMERE v200606A.

\begin{tabular}{lll}
\hline Process & Method & Reference \\
\hline Advection & $\begin{array}{l}\text { UPWIND, } \\
\text { Piecewise } \\
\text { Parabolic Method } \\
\text { scheme } \\
\text { (long-lived species) }\end{array}$ & $\begin{array}{l}\text { http://www.lmd. } \\
\text { polytechnique.fr/ } \\
\text { chimere/ Colella and } \\
\text { Woodward (1984) }\end{array}$ \\
\hline $\begin{array}{l}\text { Boundary layer } \\
\text { turbulence }\end{array}$ & Diffusion & $\begin{array}{l}\text { Troen and } \\
\text { Mahrt (1986) }\end{array}$ \\
\hline Vertical winds & $\begin{array}{l}\text { Bottom-up mass } \\
\text { balance scheme }\end{array}$ & $\begin{array}{l}\text { http://www.lmd. } \\
\text { polytechnique.fr/ } \\
\text { chimere/ }\end{array}$ \\
\hline UPWIND scheme. & $\begin{array}{l}\text { Downward flux with } \\
\text { resistance analogy }\end{array}$ & Wesely (1989) \\
\hline
\end{tabular}

troposphere. Biogenic emissions of isoprene and terpenes are parameterized following Guenther (1997) and depend on foliar density and the meteorological variables temperature and insolation. CHIMERE simulates detailed $\mathrm{NO}_{\mathrm{x}}$-VOC chemistry and takes into account aerosols. The complete chemical mechanism in CHIMERE is MELCHIOR1 (Lattuati, 1997), describing more than 300 reactions of 80 gaseous species. Photolysis rates are attenuated depending on the overhead cloud optical depth. The thermodynamic equilibrium model ISORROPIA (Nenes et al., 1998) is used to calculate the equilibrium partitioning of the gas-liquid-solid phases of various aerosol compounds (primary particles, sulfate, nitrate, ammonium, (biogenic) secondary organic aerosols, anthropogenic SOAs, and water). More details of the parameterization of the processes mentioned above can be found in Bessagnet et al. (2004) and references therein. Boundary conditions for gases are taken from monthly climatologies provided by MOZART global CTM (Horowitz et al., 2003) simulations carried out by MPI Hamburg. The boundary conditions for aerosol species are taken from the monthly mean aerosol concentrations provided by the GOCART model (Ginoux et al., 2004). Mean values of VMRs in the lowest 5 CHIMERE layers at the location of Cabauw will be compared with MAX-DOAS retrievals below.

\section{Comparisons with other independent data}

In Fig. 5, time series of the 8 components retrieved from MAX-DOAS observations with the JM1 retrieval algorithm are shown together with values calculated by CHIMERE. Overall, temporal variation patterns seen from both data sets are similar, while CHIMERE $\mathrm{NO}_{2}, \mathrm{HCHO}$, and $\mathrm{CHOCHO}$ are biased by factors of $0.6,2.5$, and 4.5 , respectively. Below, we discuss the potential of our multi-component retrievals 

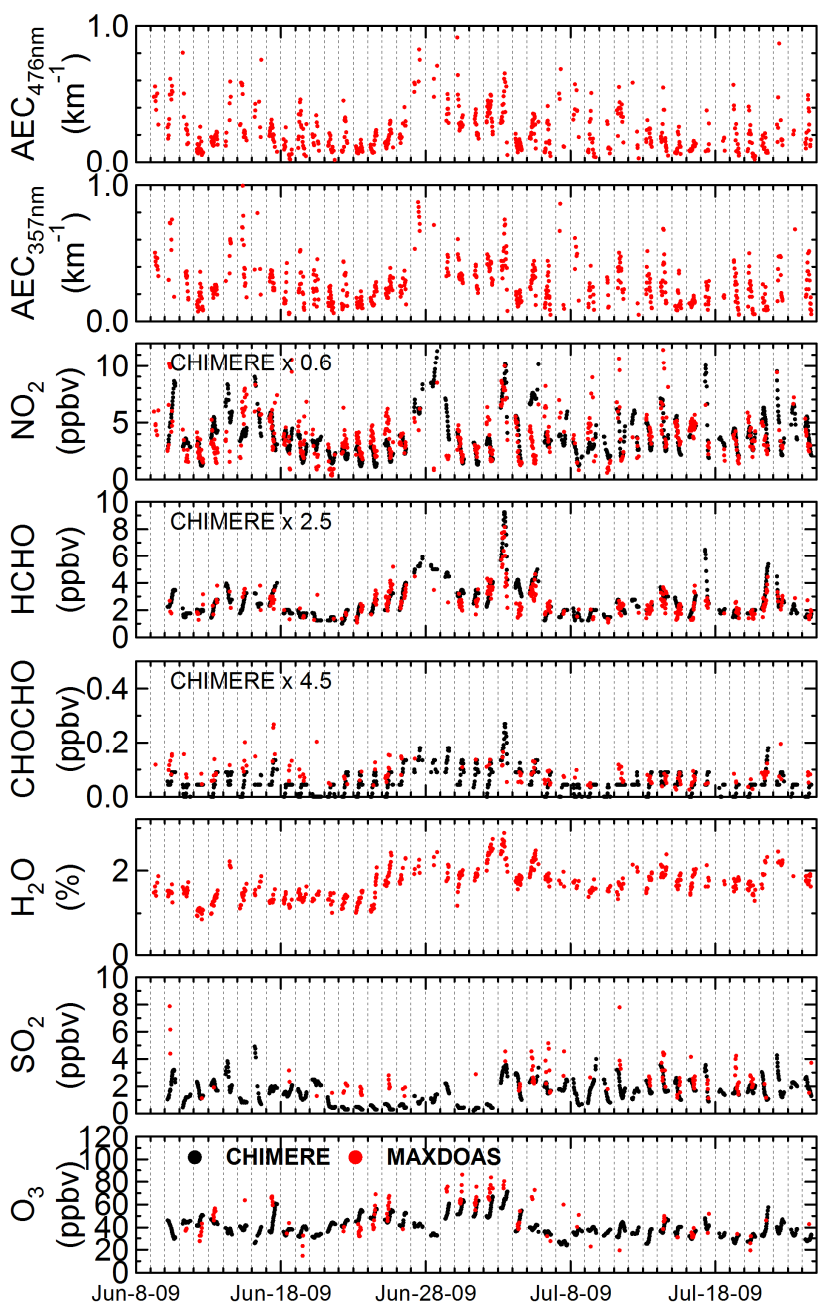

Fig. 5. Time series of the 8 components retrieved from MAXDOAS observations (red) for the $0-1 \mathrm{~km}$ layer. Also shown in black are values calculated by the CHIMERE model. CHIMERE $\mathrm{NO}_{2}$, $\mathrm{HCHO}$, and $\mathrm{CHOCHO}$ are scaled by factors of $0.6,2.5$, and 4.5 , respectively, to improve agreement (see the text for more details).

using comparisons with other independent data, including CHIMERE and in situ observations performed near the surface $(2-3 \mathrm{~m})$ and at $200 \mathrm{~m}$ on a tower placed in Cabauw.

First, AEC retrievals are discussed. During the CINDI campaign, humidified and dry nephelometer instruments, which measured aerosol scattering coefficients at various, predefined relative humidity conditions and dry conditions, respectively, were operated at the surface near the tower (Zieger et al., 2011). Adding the aerosol absorption coefficient derived from a multi-angle absorption photometer (MAAP) and an aethalometer gives AECs under ambient relative humidity conditions. Zieger et al. (2011) have compared these surface AECs with AECs corresponding to the lowest profile layer retrieved from MAX-DOAS observations by BIRA (Belgium Institute for Space Aeronomy), IUPHD (Institute for Environmental Physics of the Univer- sity of Heidelberg), MPI (Max-Planck-Institute for Chemistry), and JAMSTEC. The JAMSTEC retrieval is identical to the retrieval with JM1 presented in the present study. In the JAMSTEC retrieval, the vertical sampling is usually set to $1 \mathrm{~km}$, as mentioned above. However, while an exponentially distributed aerosol extinction profile has been assumed in the lowest 1-km layer, we selected values below $200 \mathrm{~m}$ to compare with surface AECs in a manner similar to other MAXDOAS retrievals in the study of Zieger et al. (2011). Comparisons with the four different sets of MAX-DOAS AECs all showed that the correlation was reasonably high $\left(R^{2}>0.59\right)$, but MAX-DOAS AECs tended to be higher. Comparisons with JAMSTEC AECs at $476 \mathrm{~nm}$ indicated an $R^{2}=0.74$ but a systematic positive bias by a factor of about 2.5 relative to the surface value (Zieger et al., 2011). However, additional comparisons between JAMSTEC MAX-DOAS and a CIMEL sunphotometer, in terms of AOD, show good agreement (Fig. 6a), except for some cases that show occasional high values in JAMSTEC AODs probably due to cloud contamination. This should have occurred at altitudes above $1 \mathrm{~km}$, as such high values are not seen in AEC data below $1 \mathrm{~km}$ (Fig. 6b). Similar features can also be seen for comparisons at $357 \mathrm{~nm}$ (Fig. 6c and d). We find that correlations between AECs at 357 and $476 \mathrm{~nm}$ are compact, indicating internal consistency between the retrievals at different wavelengths (Fig. 7). Thus, it can be concluded that MAX-DOAS AEC data have been retrieved reasonably. In this case, it is likely that the systematic difference seen in comparisons between MAX-DOAS and surface AEC data can be explained by vertical (and potentially horizontal) inhomogeneity of the aerosol distributions in the lower troposphere at Cabauw, where the growth of aerosols due to increasing uptake of water towards the top of the PBL could persist (Zieger et al., 2011). The MAX-DOAS AEC retrieval is expected to be improved if such spatial inhomogeneity of the aerosol distributions is considered.

During the CINDI campaign, we had a special setup for in situ $\mathrm{NO}_{2}$ instruments that were placed at different height levels on the meteorological tower in Cabauw. From 12 June to 2 July, four different in situ instruments were operated simultaneously: three instruments from Bremen University, Empa, and RIVM were placed at $3 \mathrm{~m}$, and another instrument from RIVM was placed at $200 \mathrm{~m}$. The Bremen instrument was an Ecophysics CLD 88 p chemiluminescence system with photolytic converter PLC 860 (detection limit of $50 \mathrm{ppt}$ over $60 \mathrm{~s}$ ). The Empa instrument was a modified commercial chemiluminescence analyser TEI 42C TL (Thermo Fischer Scientific Inc.). The two RIVM monitors were Model 200E chemiluminescence monitors from Teledyne Instruments. Both were equipped with photolytic converters, also from Teledyne Instruments.

To evaluate the MAX-DOAS $\mathrm{NO}_{2}$ data, we compared them with the in situ measurement data sets. To choose reasonable comparison pairs, in situ data taken within $30 \mathrm{~min}$ of MAX-DOAS data were searched. The selected in situ 

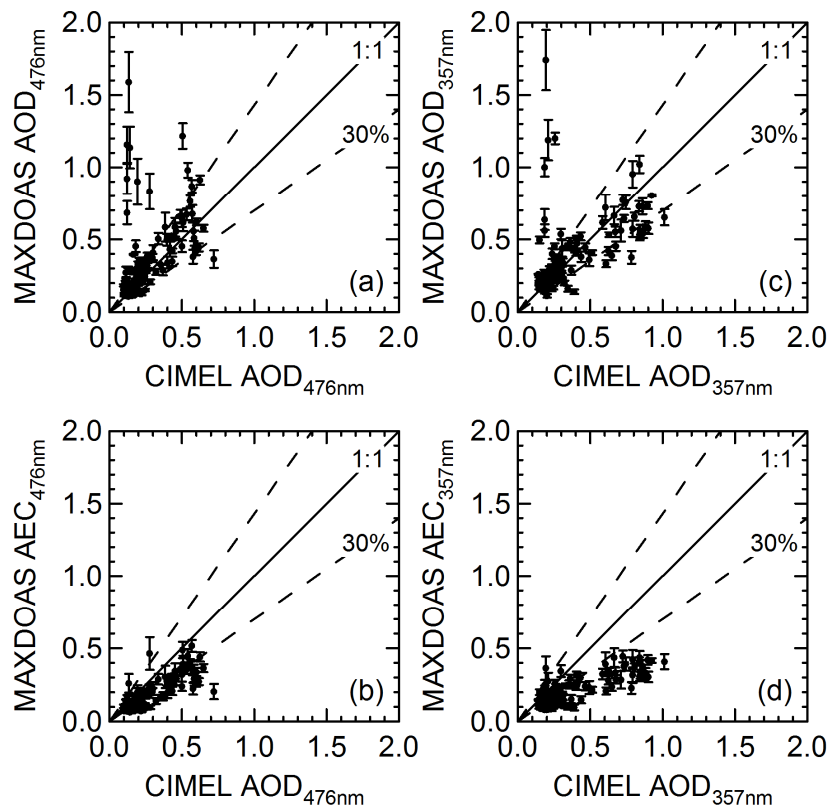

Fig. 6. Correlations between MAX-DOAS aerosol products (AOD and AEC at $0-1 \mathrm{~km}$ ) and CIMEL sunphotometer AOD data. Correlations for $476 \mathrm{~nm}$ (a and b) and $357 \mathrm{~nm}$ (c and d) are plotted.

data were averaged for each 30-min interval and compared to the corresponding MAX-DOAS data at a similar temporal resolution. The comparisons were then sorted as a function of hour. The median value for each 1-h interval was calculated and plotted in Fig. 8. This procedure has been taken to evaluate MAX-DOAS data in terms of diurnal variations, as discussed below.

As seen in Fig. 8, the early morning MAX-DOAS values were rather close to values measured by the RIVM instrument at $200 \mathrm{~m}$. The three in situ instruments at $3 \mathrm{~m}$ all show much higher values. This can be interpreted by the nighttime inversion, which kept all emissions at night close to the surface. From 07:00 to 08:00 UTC, the RIVM instrument located at $200 \mathrm{~m}$ shows an increase, because the growing boundary layer started mixing the polluted surface air to higher altitudes. The surface and 200-m observations then show almost identical values, while MAX-DOAS was still lower, probably because at this time the boundary layer height was still not very high. In the afternoon, all four instruments show values very similar to each other. Thus, we could confirm a reasonable consistency between MAXDOAS and in situ observations. Note that after 16:00 UTC the number of MAX-DOAS/in situ observation pairs compared was very small (1 to 5), whereas the number of pairs used for 05:00-15:00 UTC was as high as 15 to 25 . Only a small number of MAX-DOAS data points were available after 16:00 UTC, since spectra measured by JAMSTEC MAXDOAS could sometimes show saturation as the Sun moved close to the viewing direction or could experience very low

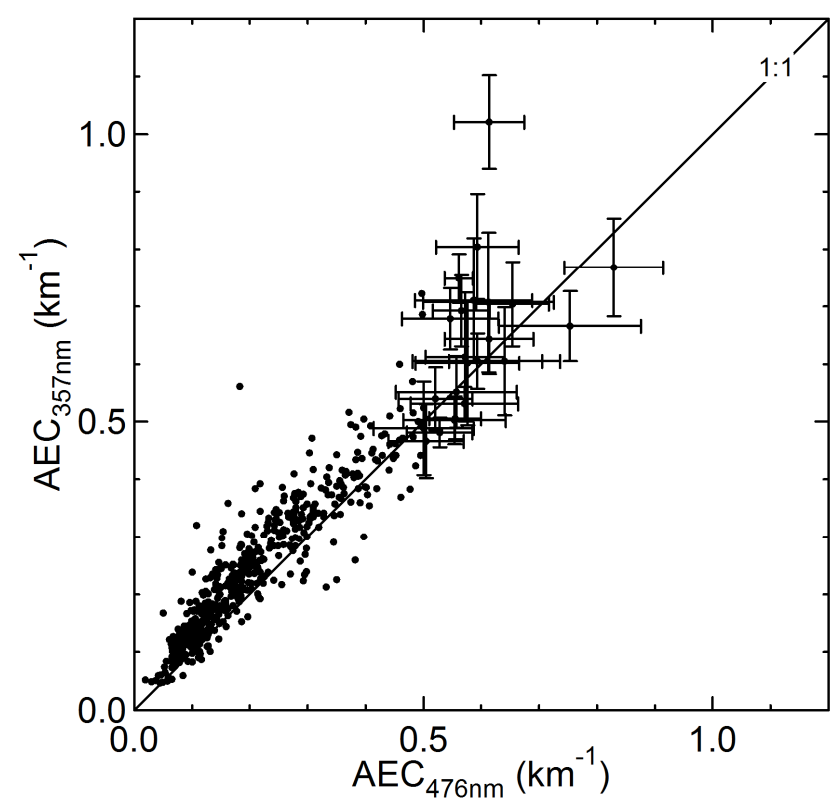

Fig. 7. Correlations between MAX-DOAS AECs at 357 and $476 \mathrm{~nm}$ for the $0-1 \mathrm{~km}$ layer. Error bars representing random errors are shown only for large values for clarity.

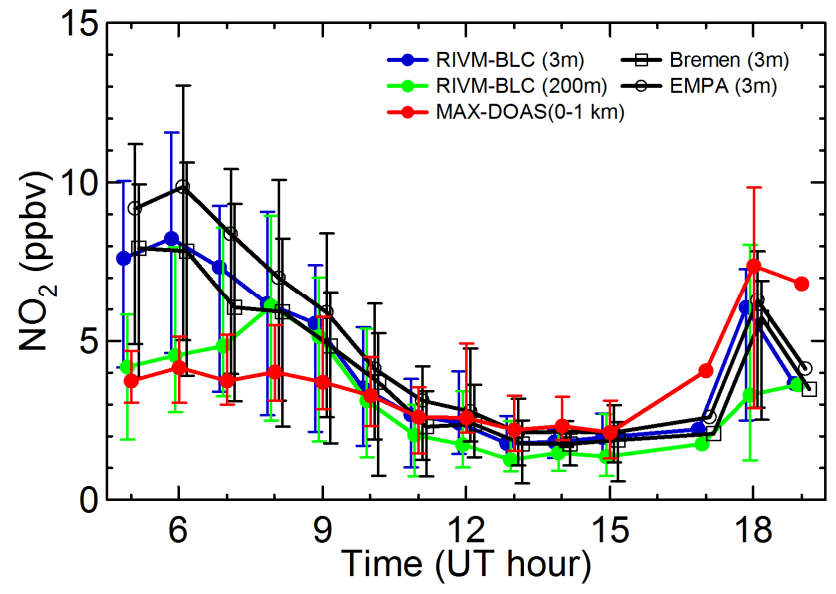

Fig. 8. Median diurnal variations of $\mathrm{NO}_{2}$ seen from MAX-DOAS and in situ observations for the period 12 June-2 July 2009, when all five different types of observations were available. MAX-DOAS data represent the mean VMR for 0-1 km, while the others represent VMRs at $3 \mathrm{~m}$, except RIVM-BLC $(200 \mathrm{~m})$ representing VMRs at $200 \mathrm{~m}$.

signals at large SZAs. Thus, it is unlikely that the diurnal variation after 16:00 UTC shown in Fig. 8 is representative for the time period from 12 June to 2 July.

To find more evidence that supports the capability of MAX-DOAS retrievals, we compared MAX-DOAS $\mathrm{NO}_{2}$ data with output of the CHIMERE model (Fig. 9). Positive correlations were obtained, but the correlation coefficient $(R)$ was moderate at 0.46 . For all the data plotted in 


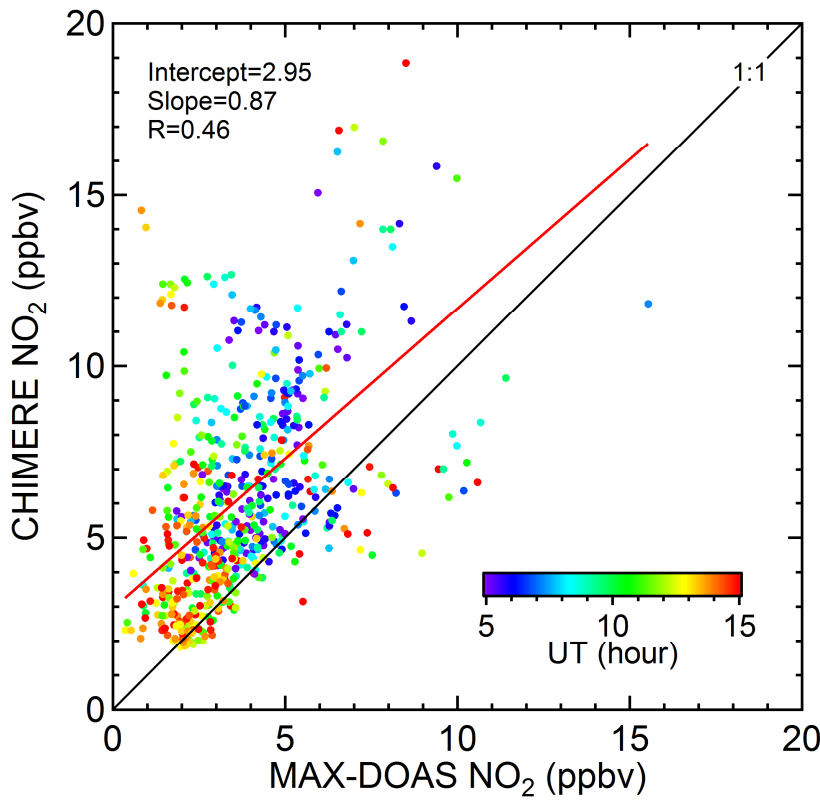

Fig. 9. Correlations between $\mathrm{NO}_{2}$ VMRs from MAX-DOAS and CHIMERE. Colors represent the time of day in UT hour. The linear least-squares fit taking into account error ranges of MAX-DOAS data is shown with the red line. The correlation coefficient $R$ is given in the plot.

Fig. 9, mean $( \pm 1 \sigma$ standard deviation $)$ values were $3.7 \pm 1.9$ and $6.2 \pm 3.0$ ppbv for MAX-DOAS and CHIMERE, respectively, indicating that the absolute value of the VMR as well as its amplitude were larger for CHIMERE than those of MAX-DOAS data by a very similar factor, about 1.6-1.7 (its inverse is $\sim 0.6$ ). Also, no clear dependence of the agreements can be seen with respect to local time (Fig. 9). Thus, a constant component seems to be a dominant factor explaining the differences seen in the comparisons, implying that the reduction in emission strengths for $\mathrm{NO}_{\mathrm{x}}$ in CHIMERE by a constant factor of 1.6-1.7 could improve agreement, unless the CHIMERE grid cell used for comparisons contains direct influences from large emission sources such as Rotterdam and Amsterdam. This is qualitatively consistent with the recent reduction in $\mathrm{NO}_{\mathrm{x}}$ emissions from Europe, as European anthropogenic emissions for the year 2003 (Visschedijk et al., 2007) have been used for CHIMERE simulations in the present study. Considering that there may be other sources yielding uncertainty in CHIMERE $\mathrm{NO}_{2}$ (such as an insufficient treatment in vertical mixing), in situ observations have provided more useful data for the evaluation of MAX-DOAS retrievals, compared to model calculations, at present.

For HCHO, however, no proper in situ observations were available, so we needed to rely on CHIMERE calculations. Surprisingly, compact positive correlations with CHIMERE $\mathrm{HCHO}$ data can readily be seen from Fig. 10. The $R$ was as high as 0.62. CHIMERE HCHO tends to be smaller by about $60 \%$ (a factor of about 2.5) (Fig. 10). Both CHIMERE and
MAX-DOAS show larger $\mathrm{HCHO}$ values at higher temperatures (Fig. 10), suggesting the production of $\mathrm{HCHO}$ from isoprene, for which more emission is expected at higher temperatures. It is likely that this process largely controls $\mathrm{HCHO}$ variations at Cabauw in June-July, probably resulting in more compact correlations of $\mathrm{HCHO}$ compared to those of $\mathrm{NO}_{2}$. As was discussed above in the $\mathrm{NO}_{2}$ comparisons, the need for improvement in emission strengths for isoprene in CHIMERE is suggested, if MAX-DOAS retrievals provide accurate HCHO VMRs.

In Fig. 10, a similar correlation analysis is made for CHOCHO as well. As isoprene emissions can be a significant source of $\mathrm{CHOCHO}$, the higher CHIMERE CHO$\mathrm{CHO}$ corresponds to higher ambient temperatures. However, CHIMERE CHOCHO is much smaller than MAXDOAS values. MAX-DOAS CHOCHO reached $0.26 \mathrm{ppbv}$, but all CHIMERE data were below 0.04 ppbv. The mean $( \pm 1 \sigma$ standard deviation) values were $0.09 \pm 0.04$ and $0.02 \pm 0.01 \mathrm{ppbv}$ for MAX-DOAS and CHIMERE, respectively, indicating a systematic difference by a factor of 4.5. For more quantitative analysis, the $\mathrm{CHOCHO}-\mathrm{HCHO}$ correlations and the $\mathrm{CHOCHO} / \mathrm{HCHO}$ ratio are investigated (Fig. 11). We found that MAX-DOAS CHOCHO tends to be higher when $\mathrm{HCHO}$ is higher. In the plumes with HCHO VMRs larger than 5 ppbv, CHOCHO VMR can exceed $0.1 \mathrm{ppbv}$, according to MAX-DOAS observations. Interestingly, the $\mathrm{CHOCHO} / \mathrm{HCHO}$ ratio was usually lower than 0.05 , which corresponds to the ratio seen from SCIAMACHY and GOME-2 observations over regions where biogenic emissions are expected (Wittrock et al., 2006; Vrekoussis et al., 2010). For all data plotted in Fig. 11, mean ratios $( \pm 1 \sigma$ standard deviation) were calculated to be $0.036 \pm 0.018$ and $0.013 \pm 0.004 \mathrm{ppbv}$ for MAX-DOAS and CHIMERE, respectively. Although more detailed investigation is needed, it is worthwhile to point out here that the fact that the ratios derived from MAX-DOAS are much closer to 0.05 than those from CHIMERE may suggest that CHOCHO-related chemistry in CHIMERE could be insufficient. To confirm this, the quantitative validation of MAXDOAS retrievals using accurate independent observations of $\mathrm{CHOCHO}$ is desirable.

In Fig. 12, MAX-DOAS $\mathrm{H}_{2} \mathrm{O}$ data are compared with surface $\mathrm{H}_{2} \mathrm{O}$ VMR data derived from dew point temperature measurements at $2 \mathrm{~m}$ at the tower in Cabauw. The dew point temperature data were converted using pressure and temperature data to $\mathrm{H}_{2} \mathrm{O} \mathrm{VMR}$. We found that the correlations were very tight, with $R=0.75$ (Fig. 12). Differences are less than $30 \%$ in most cases. Good agreement has been achieved, presumably because the DFS is high due to strong absorption by $\mathrm{H}_{2} \mathrm{O}$ available in the fitting window used $(495-515 \mathrm{~nm})$, as mentioned earlier.

In contrast to $\mathrm{H}_{2} \mathrm{O}$, the retrieval of $\mathrm{SO}_{2}$ utilizes 310 $320 \mathrm{~nm}$ in the UV, where the light intensity is much weaker than 495-515 nm, as our spectrometer has not been well optimized for UV observations. However, comparisons between 

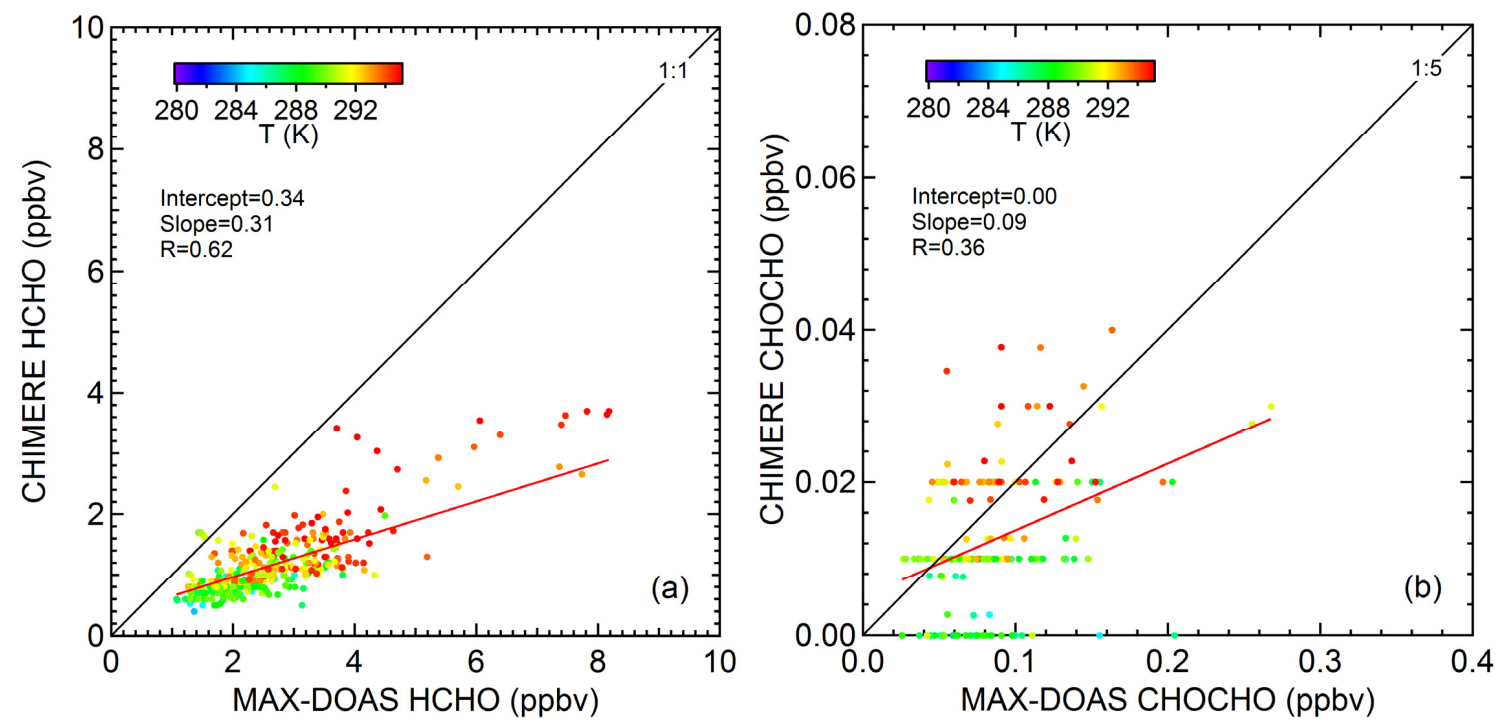

Fig. 10. MAX-DOAS-CHIMERE correlations for (a) HCHO and (b) CHOCHO. Colors indicate the ambient temperature. For each plot, the linear least-squares fit taking into account error ranges of MAX-DOAS data is shown with a red line. The correlation coefficient $R$ is given. Note that steps in CHIMERE CHOCHO values have occurred due to output at limited numerical resolution.

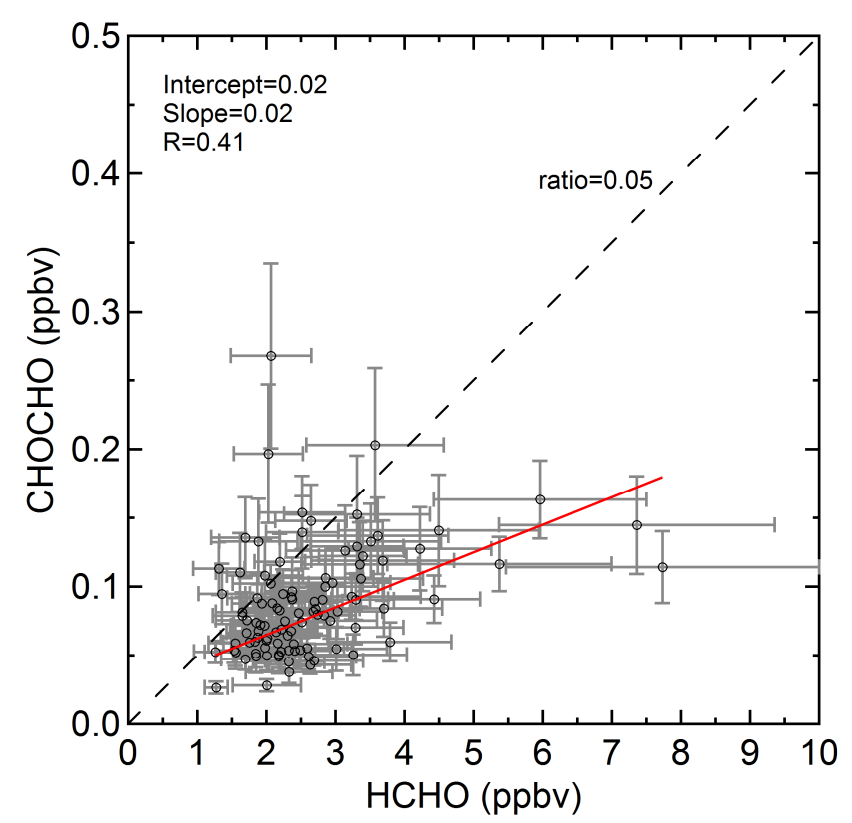

Fig. 11. Correlations between $\mathrm{CHOCHO}$ and HCHO VMRs retrieved from MAX-DOAS. The linear least-squares fit taking into account error ranges for both $\mathrm{CHOCHO}$ and $\mathrm{HCHO}$ is shown with the red line.

$\mathrm{SO}_{2}$ data derived from MAX-DOAS and CHIMERE show similar mixing ratios, at the level of ppb (Fig. 13). Positive correlations were obtained, although MAX-DOAS $\mathrm{SO}_{2}$ tends to be systematically higher than CHIMERE values, particularly when MAX-DOAS $\mathrm{SO}_{2}$ was high.

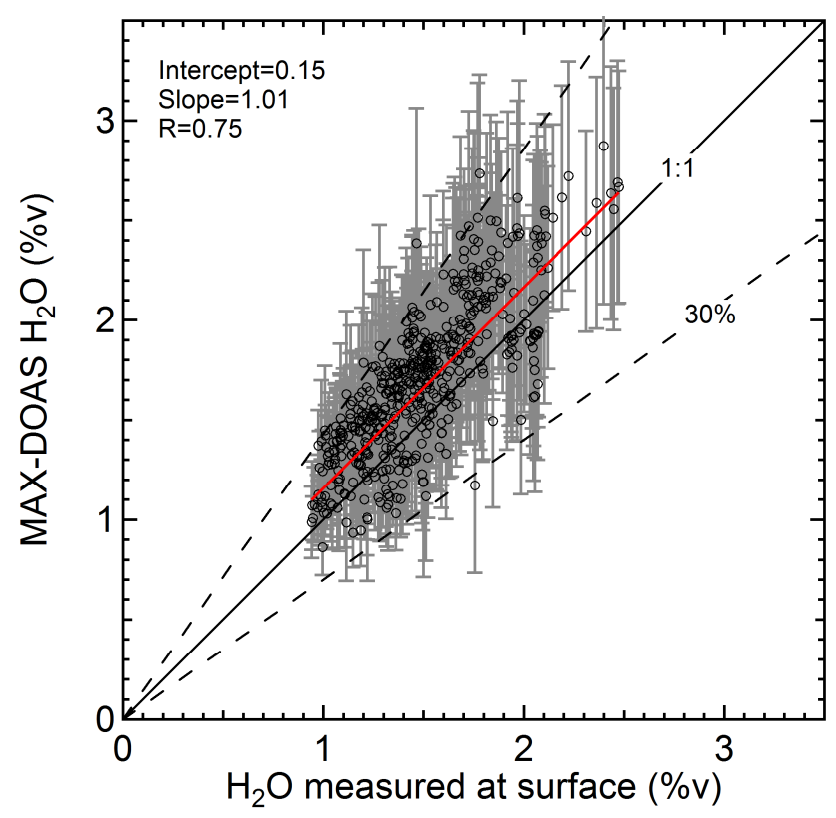

Fig. 12. Correlations of $\mathrm{H}_{2} \mathrm{O}$ VMR retrieved from MAX-DOAS with that derived from surface measurement data. The linear leastsquares fit taking into account error ranges of MAX-DOAS data is shown with the red line.

Possible explanations for these enhanced $\mathrm{SO}_{2} \mathrm{VMRs}$ seen only from MAX-DOAS data were investigated using back trajectory analysis. Figure 14 shows examples of 10-day back trajectories for air masses measured at Cabauw for cases with and without an enhancement in MAX-DOAS $\mathrm{SO}_{2}$. As can be seen from the figure, air masses with 


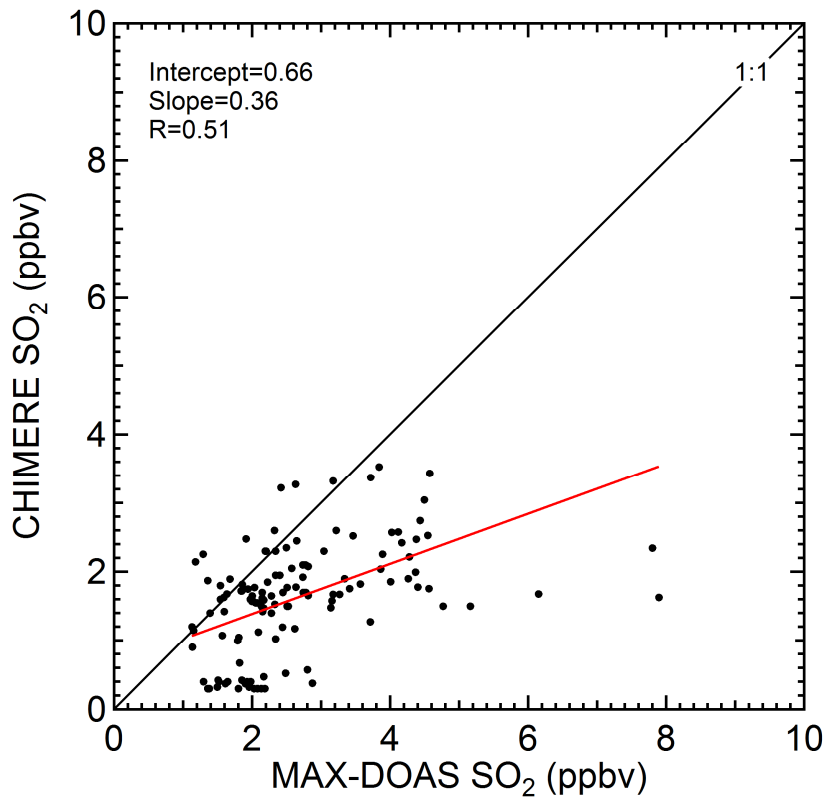

Fig. 13. Correlations between $\mathrm{SO}_{2}$ VMRs from MAX-DOAS and CHIMERE. The linear least-squares fit taking into account error ranges of MAX-DOAS data is shown with the red line.

enhanced $\mathrm{SO}_{2}$ traversed mainly over the nearby North Sea and northern Atlantic. A more robust trajectory analysis is shown in Fig. 15, where $\mathrm{SO}_{2}$ VMRs from MAX-DOAS and CHIMERE are plotted against the mean latitude and longitude of air masses over their 10-day back trajectories. For example, if the mean latitude and longitude are $47^{\circ} \mathrm{N}$ and $15^{\circ} \mathrm{W}\left(-15^{\circ} \mathrm{E}\right)$, respectively, this indicates that the air mass was at $47^{\circ} \mathrm{N}$ and $15^{\circ} \mathrm{W}$ on average over the preceding 10 days. This case corresponds to the back trajectories shown in the right panel of Fig. 14. Comparing the mean latitude and longitude with the location of Cabauw $\left(52^{\circ} \mathrm{N}\right.$ and $5^{\circ} \mathrm{E}$ ), we can infer that the air masses were most likely transported from a southwest direction, as shown in Fig. 14. As seen in Fig. 15, background levels of $\mathrm{SO}_{2}$ VMRs (cases without significant enhancement) derived from MAX-DOAS are at around $2 \mathrm{ppbv}$, in good agreement with those of the CHIMERE model. However, significant enhancements exceeding 5 ppbv can be seen only from MAX-DOAS data. The enhancements occur only at specific latitudes (around $47^{\circ} \mathrm{N}$ and $\left.60^{\circ} \mathrm{N}\right)$ and longitudes $\left(5^{\circ}-15^{\circ} \mathrm{W}\right)$. Oceanic influence is generally in the regions inferred from these latitudes and longitudes, suggesting that $\mathrm{SO}_{2}$ emissions from ships over these areas, where shipping traffic is dense, may well have led to these enhanced $\mathrm{SO}_{2}$ concentrations over Cabauw, which is only $50 \mathrm{~km}$ downwind of Rotterdam harbor.

Finally, we investigated the correlations between $\mathrm{O}_{3}$ VMRs from MAX-DOAS and CHIMERE. Although MAXDOAS $\mathrm{O}_{3}$ retrievals have additional difficulties compared to the other trace gases, as discussed above, positive correla- tions seen from the correlations encourage further continuation of the development of MAX-DOAS retrieval methods.

\section{Spatial representativeness}

In the previous section, MAX-DOAS and CHIMERE data have been compared without any consideration of spatial resolutions. To interpret such comparisons more precisely, quantification of the spatial representativeness of MAXDOAS is helpful. For this, we present a simple way (using the Pythagorean theorem) to estimate the spatial representativeness of MAX-DOAS observations for the lowest 1-kmthick layer $(D)$ as

$D=\sqrt{A_{\text {box }, \max }^{2}-1}$,

where $A_{\text {box,max }}$ is the maximum $A_{\text {box }}$ value for the $0-1 \mathrm{~km}$ layer at different ELs. The value of $D$ (in $\mathrm{km}$ ) is calculated for each retrieval.

$D$ values for two wavelengths, 357 and $476 \mathrm{~nm}$, are shown in Fig. 17. $D$ values vary with time, according mainly to the change in aerosol extinction in the lower troposphere. At $357 \mathrm{~nm}, D$ ranges between 3 and $11 \mathrm{~km}$ (mean $\pm 1 \sigma$ standard deviation is $7 \pm 2 \mathrm{~km}$ ), which corresponds to AECs ranging between 1.02 and $0.05 \mathrm{~km}^{-1}\left(0.27 \pm 0.16 \mathrm{~km}^{-1}\right)$. For $476 \mathrm{~nm}, D$ varies in the range between 3 and $15 \mathrm{~km}$ $(9 \pm 3 \mathrm{~km})$. The corresponding AECs range between 0.92 and $0.02 \mathrm{~km}^{-1}\left(0.23 \pm 0.15 \mathrm{~km}^{-1}\right)$.

The calculation of $D$ values indicates that the horizontal extent of air masses measured by MAX-DOAS at $0-1 \mathrm{~km}$ was about $10 \mathrm{~km}$, which is on the same order of magnitude of the grid size set in CHIMERE. It is also on the same order or smaller than the footprint of the satellite observations. As discussed earlier, MAX-DOAS $\mathrm{NO}_{2}$ agreed well with surface $\mathrm{NO}_{2}$ at 09:00-15:00 UTC, when the existing satellite instruments (SCIAMACHY, OMI, GOME-2) are making daily observations. This result supports the extrapolation of surface values to within the boundary layer as valid and the use of surface observations for satellite validation. In this way, it is obvious that MAX-DOAS can play a bridge-like role between surface and satellite observations. In addition, in the retrieval presented here, we have derived a $1-\mathrm{km}$ mean value for altitudes $0-1 \mathrm{~km}$. In this case, the MAX-DOAS spatial representativeness is thought to be roughly $10 \mathrm{~km}$ (horizontal) $\times 1 \mathrm{~km}$ (vertical). Compared to surface observations, much less local influence can thus be expected, such that MAX-DOAS would also be more suitable for model evaluation, as explored in this study.

\section{Summary and conclusion}

To enhance the capability of observations by MAX-DOAS, which is becoming widely used, we have developed a 

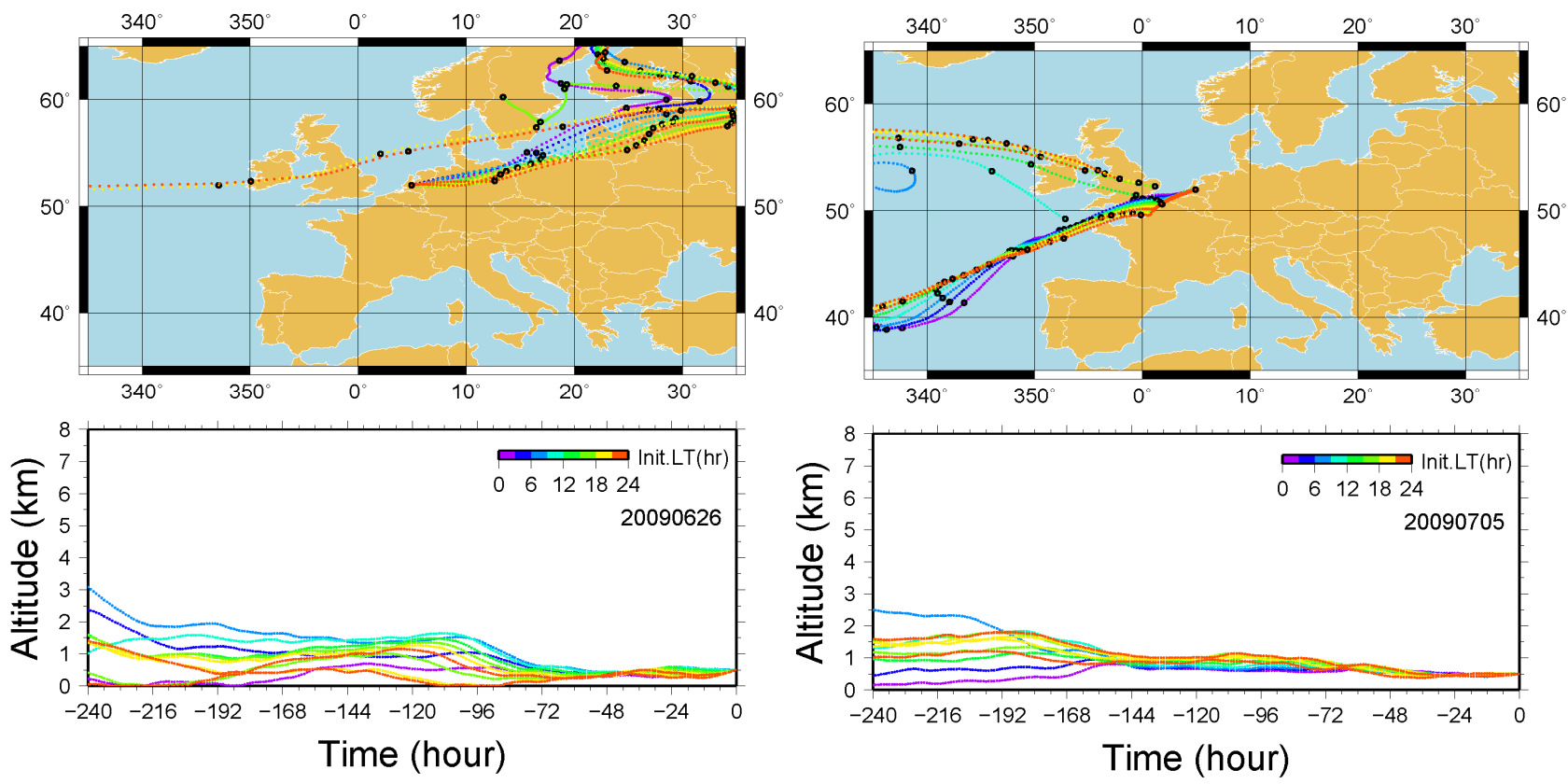

Fig. 14. Examples of back trajectories for air masses that showed (left) low and (right) high $\mathrm{SO}_{2}$ VMRs at Cabauw on 26 June and 5 July . Colors represent the local time at which the trajectory calculations started.

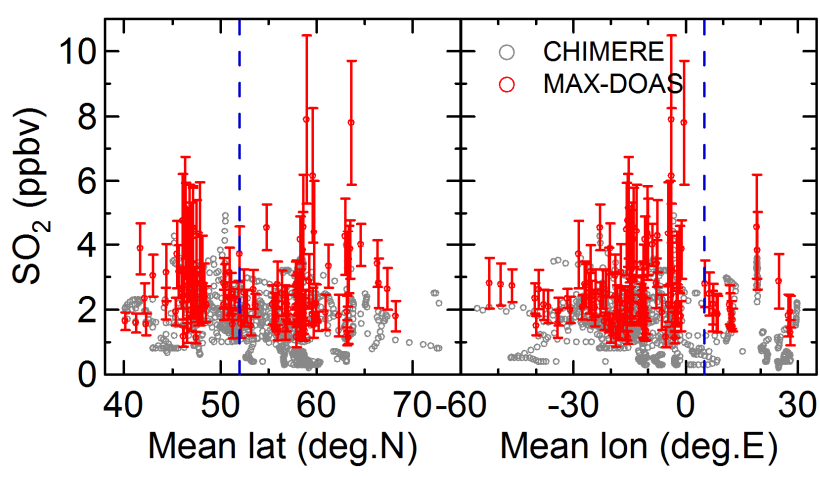

Fig. 15. $\mathrm{SO}_{2}$ VMRs from MAX-DOAS (red) and CHIMERE (gray) plotted against mean latitude and longitude of the 10-day back trajectories. Error bars represent the error range of MAX-DOAS $\mathrm{SO}_{2}$ VMR data. The location of Cabauw is indicated by vertical dashed lines.

method of retrieving lower-tropospheric vertical profile information for 8 components (AECs at two wavelengths, 357 and $476 \mathrm{~nm}$, and $\mathrm{NO}_{2}, \mathrm{HCHO}, \mathrm{CHOCHO}, \mathrm{H}_{2} \mathrm{O}, \mathrm{SO}_{2}$, and $\mathrm{O}_{3}$ VMRs). The developed retrieval algorithm (JM1) has been applied to observations performed at Cabauw, the Netherlands $\left(51.97^{\circ} \mathrm{N}, 4.93^{\circ} \mathrm{E}\right)$, during the CINDI campaign (June-July 2009), for which independent data sets, including CHIMERE model simulations and in situ observations near the surface $(2-3 \mathrm{~m})$ and at $200 \mathrm{~m}$, were available. We found that the mean $\mathrm{NO}_{2}$ VMR in the $0-1 \mathrm{~km}$ layer was usually about $3.4 \mathrm{ppbv}$. For the other components, typical values re-

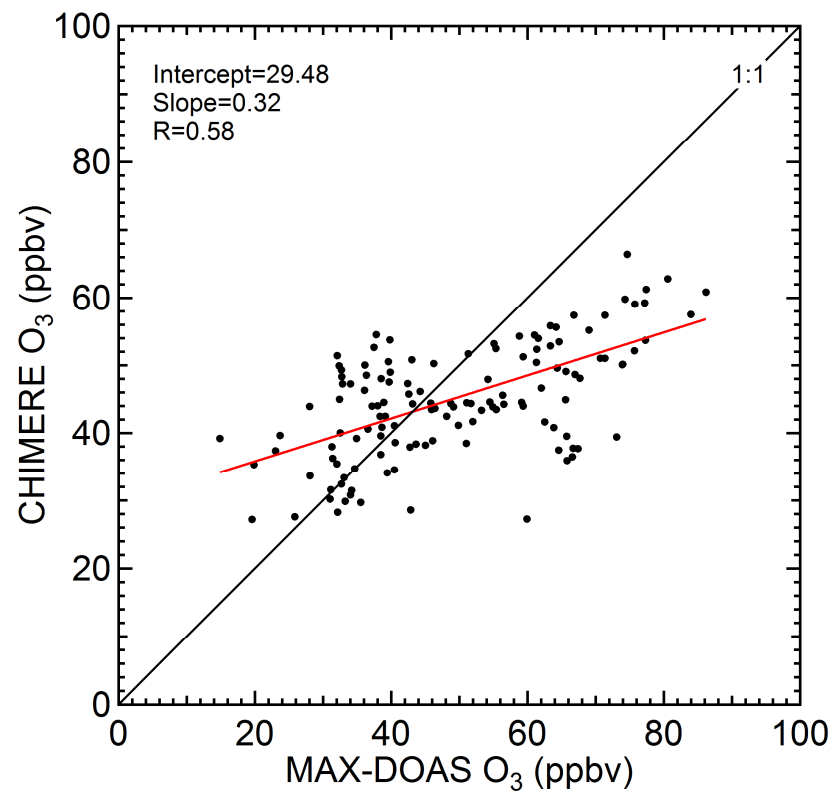

Fig. 16. Correlations between $\mathrm{O}_{3}$ VMRs from MAX-DOAS and CHIMERE. The linear least-squares fit taking into account error ranges of MAX-DOAS data is shown with the red line.

trieved are listed in Table 1. AECs were found to be systematically larger than those derived based on surface observations by nephelometer (Zieger et al., 2011), but good correspondence with CIMEL AOD measurements was found. It is likely that the systematic difference seen in comparisons 


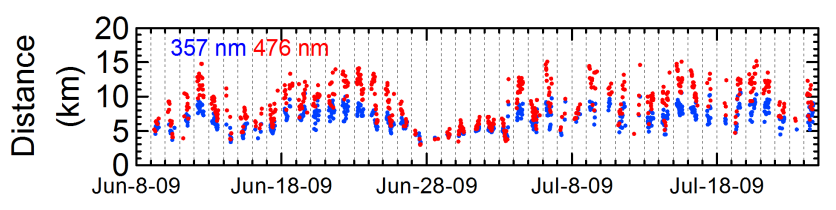

Fig. 17. Horizontal distances $(D)$ of air masses measured by MAXDOAS for the $0-1 \mathrm{~km}$ layer. $D$ values at 357 and $476 \mathrm{~nm}$ are shown in blue and red, respectively.

with surface AEC data was due to vertical inhomogeneity of aerosol distributions in the lower troposphere at Cabauw, where the growth of aerosols due to increasing uptake of water towards the top of the PBL could persist. In support of the quality of the MAX-DOAS AEC retrievals, we found that correlations between AECs at two wavelengths, 357 and $476 \mathrm{~nm}$, were compact, indicating internal consistency between the retrievals at the different wavelengths. In the early morning, mean $\mathrm{NO}_{2}$ VMRs in the $0-1 \mathrm{~km}$ layer derived from MAX-DOAS showed significantly smaller values than surface in situ observations, but the differences can be explained by the vertical inhomogeneity of $\mathrm{NO}_{2}$, since the in situ observations at $200 \mathrm{~m}$ showed intermediate variations between the MAX-DOAS and surface observations. In the afternoon, when the atmosphere below $1 \mathrm{~km}$ was thought to be wellmixed, MAX-DOAS $\mathrm{NO}_{2}$ showed good agreement with all in situ data taken at 3 and $200 \mathrm{~m}$. For all the trace gas species, $\mathrm{NO}_{2}, \mathrm{HCHO}, \mathrm{CHOCHO}, \mathrm{H}_{2} \mathrm{O}, \mathrm{SO}_{2}$, and $\mathrm{O}_{3}$, positive correlations with CHIMERE data (surface measurement data for $\mathrm{H}_{2} \mathrm{O}$ ) were found, although there were systematic differences by factors of about $0.6,2.5$, and 4.5 for $\mathrm{NO}_{2}, \mathrm{HCHO}$, and $\mathrm{CHOCHO}$, respectively, potentially due to insufficient treatments of emissions and chemistry in CHIMERE and/or the limited resolution of the model. Also, for $\mathrm{SO}_{2}$, better treatment of emissions from ships is expected to bring better agreement, as $\mathrm{SO}_{2}$ VMRs exceeding 5 ppbv were seen only in MAX-DOAS data when air masses passed mainly over the ocean, according to back trajectory analysis. For evaluating the retrievals of some species, we needed to rely a great deal on the CHIMERE model simulations, whose accuracy could not be as high as that of MAX-DOAS retrievals. However, accurate observations were not always available. The comparisons support the capability of the multi-component retrievals but at the same time indicate the need for accurate independent observations for the quantitative validation of MAX-DOAS retrievals (particularly for CHOCHO). The next step would be intercomparison within an international framework (such as CINDI), which we expect to be done in a separate paper focusing on specific species (e.g., Frieß et al., 2011). For the retrieval of the lowest 1-km layer values presented here, AMF analysis indicated that the MAXDOAS spatial representativeness can be regarded as roughly $10 \mathrm{~km}$ (horizontal) $\times 1 \mathrm{~km}$ (vertical). The horizontal distance is comparable to or better than current UV-visible satellite observations and model calculations. Thus MAX-DOAS can provide multi-component data likely useful for the evaluation of satellite observations and model calculations, playing an important role by bridging different data sets having different spatial resolutions.

Acknowledgements. We gratefully acknowledge the KNMI staff at Cabauw for their excellent technical and infrastructure support during the campaign. The CINDI campaign was for a large part funded by the ESA project CEOS Intercalibration of ground-based spectrometers and lidars (ESRIN contract 22202/09/I-EC) and the EU project ACCENT-AT2 (GOCE-CT-2004-505337). We further acknowledge the support of the EU via the GEOMON Integrated 20 Project (contract FP6-2005-Global-4-036677). We are grateful to Katrijn Clémer for helpful comments and suggestions. We thank Fred C. Bosveld for making the dew point temperature data available. PREDE, Co., Ltd is acknowledged for their technical assistance in developing the JAMSTEC MAX-DOAS instrument. This work was supported by the Japan EOS (Earth Observation System) Promotion Program of the Ministry of Education, Culture, Sports, Science and Technology (MEXT), Grant-in-Aid for Scientific Research (20710021 and 22710026), and the Global Environment Research Fund (S-7) of the Ministry of the Environment, Japan.

Edited by: J. Stutz

\section{References}

Bessagnet, B., Hodzic, A., Vautard, R., Beekmann, M., Cheinet, S., Honore, C., Liousse, C., and Rouil, L.: Aerosol modeling with CHIMERE - preliminary evaluation at the continental scale, Atmos. Environ., 38, 2803-2817, 2004.

Bobrowski, N., Hönninger, G., Galle, B., and Platt, U.: Detection of bromine monoxide in a volcanic plume, Nature, 423, 273-276, 2003.

Clémer, K., Van Roozendael, M., Fayt, C., Hendrick, F., Hermans, C., Pinardi, G., Spurr, R., Wang, P., and De Mazière, M.: Multiple wavelength retrieval of tropospheric aerosol optical properties from MAXDOAS measurements in Beijing, Atmos. Meas. Tech., 3, 863-878, doi:10.5194/amt-3-863-2010, 2010.

Colella, P. and Woodward, P. L.: The piecewise parabolic method (PPM) for gas-dynamical simulations, J. Comput. Phys., 54, 174-201, 1984.

Frieß, U., Monks, P. S., Remedios, J. J., Rozanov, A., Sinreich, R., Wagner, T., and Platt, U.: MAX-DOAS $\mathrm{O}_{4}$ measurements: A new technique to derive information on atmospheric aerosols: 2. Modeling studies, J. Geophys. Res., 111, D14203, doi:10.1029/2005JD006618, 2006.

Frieß, U., Clémer, K., Irie, H., Vlemmix, T., Wagner, T., Wittrock, F., Yilmaz, S., Zieger, P., and Apituley, A.: Intercomparison of MAX-DOAS aerosol profile retrieval algorithms during the CINDI campaign, Atmos. Meas. Tech. Discuss., in prep., 2011.

Ginoux, P., Prospero, J., Torres, O., and Chin, M.: Long-term simulation of dust distribution with the GOCART model: Correlation with the North Atlantic Oscillation, Environ. Modell. Softw., 19, 113-128, 2004. 
Greenblatt, G. D., Orlando, J. J., Burkholder, J. B., and Ravishankara, A. R.: Absorption measurements of oxygen between 330 and $1140 \mathrm{~nm}$, J. Geophys. Res., 95(11), 18577-18582, 1990.

Guenther, A.: Seasonal and spatial variations in the natural volatile organic compound emissions, Ecol. Appl., 7(1), 34-45, 1997.

Heckel, A., Richter, A., Tarsu, T., Wittrock, F., Hak, C., Pundt, I., Junkermann, W., and Burrows, J. P.: MAX-DOAS measurements of formaldehyde in the Po-Valley, Atmos. Chem. Phys., 5, 909918, doi:10.5194/acp-5-909-2005, 2005.

Hönninger, G. and Platt, U.: Observations of $\mathrm{BrO}$ and its vertical distribution during surface ozone depletion at Alert, Atmos. Environ., 36, 2481-2489, 2002.

Hönninger, G., von Friedeburg, C., and Platt, U.: Multi axis differential optical absorption spectroscopy (MAX-DOAS), Atmos. Chem. Phys., 4, 231-254, doi:10.5194/acp-4-231-2004, 2004.

Horowitz, L. W., Walters, S., Mauzerall, D., Emmonds, L. K., Rasch, P. J., Granier, C., Tie, X., Lamarquie, J.-F., Schultz, M. G., Tyndall, G. S., Orlando, J. J., and Brasseur, G.: A global simulation of tropospheric ozone and related tracers: Description and evaluation of MOZART, version 2, J. Geophys. Res., 108(D24), 4784, doi:10.1029/2002JD002853, 2003.

Inomata, S., Tanimoto, H., Kameyama, S., Tsunogai, U., Irie, H., Kanaya, Y., and Wang, Z.: Technical Note: Determination of formaldehyde mixing ratios in air with PTR-MS: laboratory experiments and field measurements, Atmos. Chem. Phys., 8, 273 284, doi:10.5194/acp-8-273-2008, 2008.

Irie, H., Kanaya, Y., Akimoto, H., Iwabuchi, H., Shimizu, A., and Aoki, K.: First retrieval of tropospheric aerosol profiles using MAX-DOAS and comparison with lidar and sky radiometer measurements, Atmos. Chem. Phys., 8, 341-350, doi:10.5194/acp-8341-2008, 2008a.

Irie, H., Kanaya, Y., Akimoto, H., Tanimoto, H., Wang, Z., Gleason, J. F., and Bucsela, E. J.: Validation of OMI tropospheric $\mathrm{NO}_{2}$ column data using MAX-DOAS measurements deep inside the North China Plain in June 2006: Mount Tai Experiment 2006, Atmos. Chem. Phys., 8, 6577-6586, doi:10.5194/acp-86577-2008, 2008b

Irie, H., Kanaya, Y., Akimoto, H., Iwabuchi, H., Shimizu, A., and Aoki, K.: Dual-wavelength aerosol vertical profile measurements by MAX-DOAS at Tsukuba, Japan, Atmos. Chem. Phys., 9, 2741-2749, doi:10.5194/acp-9-2741-2009, 2009.

Iwabuchi, H.: Efficient Monte Carlo methods for radiative transfer modeling, J. Atmos. Sci., 63, 9, 2324-2339, 2006.

Kurucz, R. L., Furenlid, I., Brault, J., and Testerman, L.: Solar flux atlas from 296 to 1300 nm, Natl. Sol. Obs., Sunspot, New Mexico, 240 pp, 1984.

Lattuati, M.: Contribution a l'etude du bilan de l'ozone tropospherique a l'interface de l'Europe et de l'Atlantique Nord: modelisation lagrangienne et mesures en altitude, These de sciences, Universite Paris 6, France, 1997.

Liu, X., Chance, K., Sioris, C. E., Spurr, R. J. D., Kurosu, T. P., and Martin, R. V.: Ozone profile and tropospheric ozone retrievals from the Global Ozone Monitoring Experiment: Algorithm description and validation, J. Geophys. Res., 110, D20307, doi:10.1029/2005JD006240, 2005.

Nenes, A., Pandis, S. N., and Pilinis, C.: ISORROPIA: A new thermodynamic equilibrium model for multiphase multicomponent inorganic aerosols, Aquat. Geochem., 4(1), 123-152, doi:10.1023/A:1009604003981, 1998.
Platt, U. and Stutz, J.: Differential Optical Absorption spectroscopy, Principles and Applications, Springer, XV, 597 p. 272 illus., 29 in color, Physics of Earth and Space Environments, ISBN 978-3540-21193-8, 2008

Rodgers, C. D.: Inverse methods for atmospheric sounding: Theory and practice, in: Ser. Atmos. Oceanic Planet. Phys., 2, edited by: Taylor, F. W., World Sci., Hackensack, N. J., 2000.

Roscoe, H. K., Van Roozendael, M., Fayt, C., du Piesanie, A., Abuhassan, N., Adams, C., Akrami, M., Cede, A., Chong, J., Clémer, K., Friess, U., Gil Ojeda, M., Goutail, F., Graves, R., Griesfeller, A., Grossmann, K., Hemerijckx, G., Hendrick, F., Herman, J., Hermans, C., Irie, H., Johnston, P. V., Kanaya, Y., Kreher, K., Leigh, R., Merlaud, A., Mount, G. H., Navarro, M., Oetjen, H., Pazmino, A., Perez-Camacho, M., Peters, E., Pinardi, G., Puentedura, O., Richter, A., Schönhardt, A., Shaiganfar, R., Spinei, E., Strong, K., Takashima, H., Vlemmix, T., Vrekoussis, M., Wagner, T., Wittrock, F., Yela, M., Yilmaz, S., Boersma, F., Hains, J., Kroon, M., Piters, A., and Kim, Y. J.: Intercomparison of slant column measurements of $\mathrm{NO}_{2}$ and $\mathrm{O}_{4}$ by MAX-DOAS and zenith-sky UV and visible spectrometers, Atmos. Meas. Tech., 3, 1629-1646, doi:10.5194/amt-3-1629-2010, 2010.

Sinreich, R., Volkamer, R., Filsinger, F., Frieß, U., Kern, C., Platt, U., Sebastián, O., and Wagner, T.: MAX-DOAS detection of glyoxal during ICARTT 2004, Atmos. Chem. Phys., 7, 1293-1303, doi:10.5194/acp-7-1293-2007, 2007

Takashima, H., Irie, H., Kanaya, Y., Shimizu, A., Aoki, K. and Akimoto, H.: Atmospheric aerosol variations at Okinawa Island in Japan observed by MAX-DOAS using a new cloud-screening method, J. Geophys. Res., 114, D18213, doi:10.1029/2009JD011939, 2009.

Troen, I. and Mahrt, L.: A simple model of the atmospheric boundary layer: Sensitivity to evaporation, Bound.-Layer Meteorol., 37, 129-148, 1986.

Visschedijk, A., Zandveld, P., and van der Gon, H. D.: A High Resolution Gridded European Emission Database for the EU Integrated Project GEMS, Technical Report TNO-report 2007 AR0233/B, TNO, Apeldoorn, 2007.

Vrekoussis, M., Wittrock, F., Richter, A., and Burrows, J. P.: GOME-2 observations of oxygenated VOCs: what can we learn from the ratio glyoxal to formaldehyde on a global scale?, Atmos. Chem. Phys., 10, 10145-10160, doi:10.5194/acp-1010145-2010, 2010.

Wagner, T., Dix, B., von Friedeburg, C., Frieß, U., Sanghavi, S., Sinreich, R., and Platt, U.: MAX-DOAS $\mathrm{O}_{4}$ measurements: A new technique to derive information on atmospheric aerosols - Principles and information content, J. Geophys. Res., 109, D22205, doi:10.1029/2004JD004904, 2004.

Wagner, T., Burrows, J. P., Deutschmann, T., Dix, B., von Friedeburg, C., Frieß, U., Hendrick, F., Heue, K.-P., Irie, H., Iwabuchi, H., Kanaya, Y., Keller, J., McLinden, C. A., Oetjen, H., Palazzi, E., Petritoli, A., Platt, U., Postylyakov, O., Pukite, J., Richter, A., van Roozendael, M., Rozanov, A., Rozanov, V., Sinreich, R., Sanghavi, S., and Wittrock, F.: Comparison of box-airmass-factors and radiances for Multiple-Axis Differential Optical Absorption Spectroscopy (MAX-DOAS) geometries calculated from different UV/visible radiative transfer models, Atmos. Chem. Phys., 7, 1809-1833, doi:10.5194/acp-7-1809-2007, 2007. 
Wagner, T., Deutschmann, T., and Platt, U.: Determination of aerosol properties from MAX-DOAS observations of the Ring effect, Atmos. Meas. Tech., 2, 495-512, doi:10.5194/amt-2-4952009, 2009.

Wesely, M. L.: Parameterization of surface resistances to gaseous dry deposition in regional-scale numerical models. Atmos. Environ., 23, 1293-1304, 1989.

Wittrock, F., Oetjen, H., Richter, A., Fietkau, S., Medeke, T., Rozanov, A., and Burrows, J. P.: MAX-DOAS measurements of atmospheric trace gases in Ny-Ålesund - Radiative transfer studies and their application, Atmos. Chem. Phys., 4, 955-966, doi:10.5194/acp-4-955-2004, 2004.
Wittrock, F., Richter, A., Oetjen, H., Burrows, J. P., Kanakidou, M., Myriokefalitakis, S., Volkamer, R., Beirle, S., Platt, U., and Wagner, T.: Simultaneous global observations of glyoxal and formaldehyde from space, Geophys. Res. Lett., 33, L16804, doi:10.1029/2006GL026310, 2006.

Zieger, P., Weingartner, E., Henzing, J., Moerman, M., de Leeuw, G., Mikkilä, J., Ehn, M., Petäjä, T., Clémer, K., van Roozendael, M., Yilmaz, S., Frieß, U., Irie, H., Wagner, T., Shaiganfar, R., Beirle, S., Apituley, A., Wilson, K., and Baltensperger, U.: Comparison of ambient aerosol extinction coefficients obtained from in-situ, MAX-DOAS and LIDAR measurements at Cabauw, Atmos. Chem. Phys., 11, 2603-2624, doi:10.5194/acp11-2603-2011, 2011. 